\title{
Stabilizing greenhouse gas concentrations at low levels: an assessment of reduction strategies and costs
}

\author{
Detlef P. van Vuuren • Michel G. J. den Elzen • \\ Paul L. Lucas • Bas Eickhout • Bart J. Strengers • \\ Bas van Ruijven • Steven Wonink • Roy van Houdt
}

Received: 12 December 2005 / Accepted: 9 May 2006 /

Published online: 13 February 2007

(C) Springer Science + Business Media B.V. 2007

\begin{abstract}
On the basis of the IPCC B2, A1b and B1 baseline scenarios, mitigation scenarios were developed that stabilize greenhouse gas concentrations at 650, 550 and 450 and subject to specific assumptions $-400 \mathrm{ppm} \mathrm{CO}_{2}$-eq. The analysis takes into account a large number of reduction options, such as reductions of non- $\mathrm{CO}_{2}$ gases, carbon plantations and measures in the energy system. The study shows stabilization as low as $450 \mathrm{ppm} \mathrm{CO}_{2}$-eq. to be technically feasible, even given relatively high baseline scenarios. To achieve these lower concentration levels, global emissions need to peak within the first two decades. The net present value of abatement costs for the $\mathrm{B} 2$ baseline scenario (a medium scenario) increases from $0.2 \%$ of cumulative GDP to $1.1 \%$ as the shift is made from 650 to $450 \mathrm{ppm}$. On the other hand, the probability of meeting a two-degree target increases from $0 \%-10 \%$ to $20 \%-70 \%$. The mitigation scenarios lead to lower emissions of regional air pollutants but also to increased land use. The uncertainty in the cost estimates is at least in the order of $50 \%$, with the most important uncertainties including land-use emissions, the potential for bio-energy and the contribution of energy efficiency. Furthermore, creating the right socio-economic and political conditions for mitigation is more important than any of the technical constraints.
\end{abstract}

\section{Introduction}

Climate change appears to be among the most prominent sustainability problems of this century. IPCC's Third Assessment Report concludes that earth's climate system has demonstrably changed since the pre-industrial era and that - without climate policy responses changes in the global climate are likely to become much larger, with expected increases in global temperature in the 2000-2100 period ranging from 1.4 to $5.8{ }^{\circ} \mathrm{C}$ (IPCC 2001). Article 2 of the United Nations Framework Convention on Climate Change (UNFCCC) states

D. P. van Vuuren $(\bowtie) \cdot$ M. G. den Elzen • P. L. Lucas $•$

B. Eickhout · B. J. Strengers $\cdot$ B. van Ruijven $\cdot$ S. Wonink $\cdot$ R. van Houdt

Netherlands Environmental Assessment Agency (MNP),

P.O. Box 303, 3720 AH Bilthoven, The Netherlands

e-mail: Detlef.van.Vuuren@mnp.nl 
as its ultimate objective: "Stabilization of greenhouse gas (GHG) concentrations in the atmosphere at a level that would prevent dangerous anthropogenic interference with the climate system." However, what constitutes a non-dangerous level is an open question, as this depends on all kinds of uncertainties in the cause-effect chain of climate change and on political decisions about the risks to be avoided. Some of the recent literature suggests that climate risks could already be substantial for an increase of $1-3{ }^{\circ} \mathrm{C}$ compared to pre-industrial levels (see Corfee et al 2005; ECF and PIK 2004; Leemans and Eickhout 2004; Mastandrea and Schneider 2004; MNP 2005; O’Neill and Oppenheimer 2002). As one of the political actors, the EU has adopted the climate policy goal of limiting the temperature increase to a maximum of $2{ }^{\circ} \mathrm{C}$ compared to pre-industrial levels (EU 1996, 2005). However, uncertainties still allow for other interpretations of what constitutes dangerous climate change in the context Article 2. Actors may, in their interpretation, weigh factors like the risks of climate change adaptation costs and limits and the costs and effectiveness of mitigation action.

Apart from the temperature target, the required level of emission reduction also depends on the uncertain relationship between atmospheric GHG concentrations and temperature increase, in other words 'climate sensitivity'. Several probability-distribution functions (PDF) for climate sensitivity have been published in recent years, each indicating a broad range of values for climate sensitivity that still have a reasonable likelihood (for example Murphy 2004; Wigley and Raper 2001). Several authors indicated that these PDFs can be translated into a risk approach towards climate change (Azar and Rodhe 1997; den Elzen and Meinshausen 2005; Hare and Meinshausen 2004; Meinshausen 2006; Richels et al. 2004; Yohe et al. 2004). These studies show that a high degree of certainty in terms of achieving a $2{ }^{\circ} \mathrm{C}$ temperature target is likely to require stabilization at low GHG concentration (for instance a probability greater than $50 \%$ requires stabilization at least below $450 \mathrm{ppm} \mathrm{CO}_{2}$ eq. ${ }^{1}$ ). The stabilization of GHG concentrations at such a low level will require drastic emission reductions compared to the likely course of emissions in the absence of climate policies. Even for more modest concentration targets such as $650 \mathrm{ppm} \mathrm{CO}_{2}$-eq., emissions in 2100 will generally need to be reduced by about $50 \%$ compared to probable levels in the absence of a climate policy (IPCC 2001).

A large number of scenario studies have been published that aim to identify mitigation strategies for achieving different levels of GHG emission reductions (see among others Hourcade and Shukla 2001; Morita and Robinson 2001). However, most of these studies have focused on reducing only the energy-related $\mathrm{CO}_{2}$ emissions, and disregarded abatement options that reduce non- $\mathrm{CO}_{2}$ gases and the use of carbon plantations. Furthermore, the number of studies looking at stabilization levels below $550 \mathrm{ppm} \mathrm{CO}_{2}$-eq. is very limited. A few studies exist that explore the feasibility to stabilize $\mathrm{CO}_{2}$ alone at $350-450 \mathrm{ppm} \mathrm{CO}_{2}$; the lowest multi-gas stabilization studies in literature focus on $550 \mathrm{ppm}$ $\mathrm{CO}_{2}$-eq. (see Section 2). This implies that very little information exists on mitigation strategies that could stabilize GHG concentrations at the low levels required to achieve a $2-$ $3{ }^{\circ} \mathrm{C}$ temperature target with a high degree of certainty. As a matter of fact, even the number of studies looking at stabilizing at $550 \mathrm{ppm} \mathrm{CO}$-eq. is far lower than for higher stabilization targets (see Morita et al. 2000; Swart et al. 2002). Finally, most earlier studies have not

\footnotetext{
1 ' $\mathrm{CO}_{2}$ equivalence' expresses the radiative forcing of other anthropogenic radiative forcing agents in terms of the equivalent $\mathrm{CO}_{2}$ concentration that would result in the same level of forcing. In this paper, the definition of $\mathrm{CO}_{2}$-eq. concentrations includes the Kyoto gases, tropospheric ozone and sulphur aerosols.
} 
considered the more recent mitigation options being discussed in the context of ambitious emission reduction, such as hydrogen and carbon capture and storage (CCS) (Edmonds et al. 2004; IEA 2004a; IPCC 2005). Given current insights into climate risks and the state of the mitigation literature, there is a very clear and explicit need for comprehensive scenarios that explore different long-term strategies to stabilize GHG emissions at low levels (Metz and van Vuuren 2006; Morita and Robinson 2001).

This paper explores different multi-gas stabilization scenarios for concentration levels for which no scenarios are currently available (below 550 ppm $\mathrm{CO}_{2}$-eq.). In order to study the impact of different stabilization levels, we have chosen to explore scenarios for a range of concentrations levels (i.e., 650,550 and $450 \mathrm{ppm} \mathrm{CO}_{2}$-eq.) and under specific assumptions (400 ppm $\mathrm{CO}_{2}$-eq.). As such, the study also goes beyond our own research that did not cover stabilization scenarios below 550 ppm $\mathrm{CO}_{2}$-eq. (van Vuuren et al. 2006b). ${ }^{2}$ The paper adds to the existing literature in an important way by exploring pathways to those GHG stabilization levels required for achieving global mean temperature change targets of $2-3^{\circ}$ $\mathrm{C}$ with a high degree of certainty. We specifically focus on the following questions:

- What portfolios of measures could constitute promising strategies for stabilizing GHG concentrations at 650,550 and 450 ppm $\mathrm{CO}_{2}$-eq. and below?

- What are the cost levels involved in such strategies and what are the implications for the energy sector, investment strategies and fuel trade?

- How do uncertainties in the potentials and costs of various options play a role in terms of the costs and selection of a portfolio of measures?

The focus of this paper will be on mitigation strategies, abatement costs and climate consequences from a global perspective. In a related paper, we focus on the regional costs and abatement strategies ${ }^{3}$ (den Elzen et al. 2006). For costs, we consider direct abatement costs due to climate policy and do not capture macro-economic costs; for benefits we focus on the impact on global mean temperature and co-benefits for air pollutants. In our analysis, we deliberately use an integrated approach, dealing with a wide range of issues that are relevant in the context of stabilization scenarios including land use consequences and changes in the energy system. Although several of these issues have been studied earlier for single stabilization scenarios, here we would like to see how they are related to the GHG stabilization level.

The analysis was conducted using the IMAGE 2.3 model framework, including the energy model TIMER 2.0 coupled to the climate policy model FAIR-SiMCaP (for model description, (see Section 3). A similar framework (using FAIR instead of FAIR-SiMCaP) has been used earlier to study mitigation strategies, for example in the context of EU climate policy targets (Criqui et al. 2003; van Vuuren et al. 2003). This model framework was designed to provide a broad description of the issues involved in the chain of events causing climate change. It covers a broad range of emission sources (and therefore abatement options), covering not only the energy sector but also land use, forestry, and industry. It is therefore suitable for studying the type of mitigation strategies required to stabilize radiative forcing from GHG and for studying the possible environmental and economic consequences of such strategies. We use this framework to explore stabilization

\footnotetext{
${ }^{2}$ Earlier we published emission profiles that would lead to stabilization at low GHG concentration levels, but that study did not look into the question how these emission profiles could be reached (den Elzen and Meinshausen 2005).

${ }^{3}$ Regional costs also depend on possible agreements about regional reduction targets and they therefore constitute a separate topic that cannot be dealt with in the context of this paper.
} 
strategies based on three different baseline scenarios, i.e., updated implementations of the IPCC SRES B2, B1 and A1b scenarios. We perform an extensive sensitivity analysis for the different options to map out some of the main uncertainties.

The paper is structured as follows. First, we provide a brief overview of earlier work on stabilization scenarios. We then explain the methods used to develop the new scenarios before discussing the first results from our three default scenarios and the associated benefits and cobenefits. Next, we present the results of our uncertainty analysis and also address the question of whether it is possible to reduce emissions to levels even lower than $450 \mathrm{ppm} \mathrm{CO}_{2}$-eq. After that, we compare our results to earlier studies and examine the implications of the uncertainties that have been identified. Finally, we present our overall findings.

\section{Earlier work on stabilization scenarios}

A large number of scenario studies have been published that have explored global mitigation strategies for stabilizing GHG concentrations. A recent inventory estimated the number of published GHG emission scenarios at a few hundred, although a large majority of these are baseline scenarios (scenarios that do not take the effect of climate policy into account) (NIES 2005). ${ }^{4}$ In the literature on mitigation scenarios, there are a number of recurring themes. These include:

- The issue of stabilization targets and overshoot;

- The identification of overall cost levels of stabilization;

- The issue of timing (early action or delayed response), partly in relation to technology development;

- The role of individual technologies and mitigation measures.

In this paper, we will briefly discuss the available literature and indicate how these issues are handled. The IPCC Third Assessment Report (TAR) (Hourcade and Shukla 2001; Morita and Robinson 2001) provides an overview of the stabilization scenarios as available at that time.

On the issue of stabilization targets, many studies in the past have focused on stabilizing $\mathrm{CO}_{2}$ concentration levels. Consistent with this, new multi-gas studies mostly focus on the comparable measure of stabilizing radiative forcing (expressed in $\mathrm{W} / \mathrm{m}^{2}$ or $\mathrm{CO}_{2}$-eq.) (van Vuuren et al. 2006c). Alternatively, some studies look at temperature increase targets (as they are more directly related to impacts). One implication of using a temperature target, however, is the higher level of uncertainty relating to mitigation action (Matthews and van Ypersele 2003; Richels et al. 2004). Another issue is that staying below a certain temperature level with a specific likelihood can either be achieved by (a) stabilizing at a certain radiative forcing level or by (b) peaking at somewhat higher levels, immediately followed by a reduction of the forcing level ('overshoot scenarios'). The second

\footnotetext{
${ }^{4}$ It is possible to distinguish between scenarios and emission pathways. Emission pathways focus solely on emissions, whereas scenarios represent a more complete description of possible future states of the world. The literature distinguishes between baseline, and mitigation or stabilization scenarios. The first category includes scenarios without explicit new climate policies. These scenarios do, however, need to assume policies in other fields than climate policy, and these may still unintentionally have a significant impact on GHG emissions (e.g., other environmental policies, trade policies). Mitigation scenarios (or climate policy scenarios) purposely assume climate policies to explore their impact. Stabilization scenarios are a group of scenarios that include mitigation measures intended to stabilize atmospheric GHG concentrations.
} 
strategy prevents some of the temperature increase that will occur in the longer term (den Elzen and Meinshausen 2005; Meinshausen 2006; Wigley 2003). In general, these overshoot scenarios will involve lower costs than the corresponding stabilization scenarios. For the lower stabilization levels, overshoot scenarios are the only feasible scenarios since current concentrations have either already passed these levels, or will do so in the very near future. In broad terms, the current scenario literature covers stabilization levels from 750 to 450 ppm $\mathrm{CO}_{2}$ for ' $\mathrm{CO}_{2}$-only' studies. There are only a few studies that have looked into stabilizing concentrations at lower concentration levels. Exceptions include the work of Nakicenovic and Riahi (2003), Azar et al. (2006), and Hijoka et al. (2006). These studies show that, in principle, low stabilization levels (below $450 \mathrm{ppm} \mathrm{CO}_{2}$ ) can be achieved at mitigation costs in the order of $1 \%-2 \%$ of GDP. However, these studies started from relatively low-emission baseline scenarios.

In multi-gas studies, the range is actually much more limited, with studies typically only looking at $650 \mathrm{ppm} \mathrm{CO}_{2}$-eq. (van Vuuren et al. 2006c; Weyant et al. 2006). The lowest scenarios currently found in the literature aim at $550 \mathrm{ppm} \mathrm{CO}_{2}$-eq. (Criqui et al. 2003; van Vuuren et al. 2006b) and these only give a very low level of probability to limit temperature increase to less than $2{ }^{\circ} \mathrm{C}$. For a range of probability-distribution functions (PDF), Hare and Meinshausen (2004) estimated the probability to be about $0 \%-30 \%$. The probability of staying within $2.5{ }^{\circ} \mathrm{C}$ is $10 \%-50 \%$. A $50 \%$ probability (on average) of staying within $2{ }^{\circ} \mathrm{C}$ is obtained for $450 \mathrm{ppm} \mathrm{CO}_{2}$-eq. The only multi-gas studies in the literature that are currently exploring the consequences of aiming for such low stabilization levels are emission pathway studies that do not specify the type of mitigation measures leading to the required emissions reductions (den Elzen and Meinshausen 2005; Meinshausen 2006; Meinshausen et al. 2006).

Different metrics are used for the costs of climate policies. Partial equilibrium models (such as energy system models) generally report costs as increased energy system costs or abatement costs (these are annual costs that can be expressed as percentages of GDP). General equilibrium models, by contrast, generally report reductions of GDP or private consumption relative to the baseline scenario. For the $30-40$ stabilization scenarios analyzed in TAR, the assessment found very small costs for stabilizing at $750 \mathrm{ppm}$ but stated typical GDP losses of $1 \%-4 \%$ for $450 \mathrm{ppm}$ (Hourcade and Shukla 2001). Costs were found to be a function of the GHG stabilization level and the baseline emission scenario. This implies that socio-economic conditions, including policies outside the field of climate policy, are just as important for stabilization costs as climate policies.

The issue of the timing of the abatement effort was initiated by Hamitt et al. (1992) and later by Wigley et al. (1996). Wigley et al. (1996) argued that their scenarios, which postponed abatement action compared to earlier pathways developed by IPCC, were more cost-effective because of the benefits of technology development, more $\mathrm{CO}_{2}$ absorption by the biosphere and oceans, and discounting future costs. Their arguments were confirmed in the analysis of the EMF-14 (energy modeling forum) study (as reported by Hourcade and Shukla 2001). Other authors, however, responded that this conclusion depends on the assumptions about discounting, technological change, inertia and uncertainty (Azar 1998; Azar and Dowlatabadi 1999; Ha-Duong et al. 1997). For low-range concentration targets, den Elzen and Meinshausen (2005) reported that delaying the peak in global emissions beyond 2020 leads to very high reduction rates later in the century and therefore to probable high costs. Assuming induced technology change (instead of exogenous technological progress simply as function of time) and explicit capital turnover rates could lead to a preference for early action, or at least a spread of the reduction effort over the century as a whole (see also van Vuuren et al. 2004). The debate about optimal timing is still ongoing. Yohe et al. (2004) recently showed that hedging strategies (i.e., cost-optimal reduction 
pathways incorporating the risk of more, or less, stringent action later in the century if new evidence comes in) to deal with uncertainties may lead to relatively early reduction pathways leaving as many options open as possible (Berk et al. 2002).

Recently, a lot of attention has been paid to extending the number of reduction options considered in scenario analysis. One possibility is the inclusion of non- $\mathrm{CO}_{2} \mathrm{GHGs}$. The energy modeling forum (EMF-21) performed a model comparison study, showing that extending the reduction options from $\mathrm{CO}_{2}$ only to include other GHGs can reduce costs by about a third (van Vuuren et al 2006c; Weyant et al. 2006). Recent publications also put forward several new technologies that could be pivotal in mitigation strategies. First of all, CCS could play an important role in reducing GHG emissions in the power sector. This technology could become cost-effective at emission permit prices of around 100-200 US\$/ tC (IPCC 2005) and therefore reduce mitigation costs considerably (Edmonds et al. 2004; IEA 2004a). Recent work on hydrogen as an energy carrier has shown that hydrogen may also reduce mitigation costs but this conclusion depends very much on the assumption of technology development (Edmonds et al. 2004). Bio-energy in combination with CCS could be an attractive technology if very ambitious stabilization targets are adopted (Azar et al. 2006). Finally, the debate is still ongoing about whether accounting for technology change (induced learning vs exogenous assumptions) in itself results in different conclusions about optimal climate policies. Some studies claim that induced technological change leads to very significant cost reductions and justifies a preference for early action (Azar and Dowlatabadi 1999; Barker et al. 2005). Others report fewer benefits and/or no impact on timing (Manne and Richels 2004).

What are the implications of the current state of knowledge for this study? The most important aim of this study is to determine whether a multi-gas approach can be used to achieve the stabilization of GHG concentration at lower levels than those usually considered in mitigation studies. Our scenarios, based on the emission pathways developed by den Elzen and Meinshausen (2005) and den Elzen et al. (2007) should be characterized as mediumterm pathways (since they are neither early nor delayed). In terms of the objective of climate policy, we focus on the stabilization of concentration (and thus not temperature) to increase the comparability with other studies. den Elzen et al. (2007) indicate how the results of the emission pathways compare to alternative peaking scenarios. In view of the debate about new mitigation options, the model framework used in this study covers a large range of mitigation options (such as non- $\mathrm{CO}_{2}, \mathrm{CCS}$, carbon plantations, hydrogen, bioenergy, nuclear, solar and wind power), and several technologies are described in terms of induced technological change. The aim of this study is to identify a portfolio of measures that contribute to the reduction of emissions with the aim of achieving the selected concentration targets, and to assess the costs associated with this portfolio. Given the major uncertainties involved in each of the mitigation options, we will analyze how some of these uncertainties impact the overall results.

\section{Methodology}

\subsection{Overall methodology}

For the construction of the stabilization scenarios, we use an interlinked modelling framework consisting of the IMAGE 2.3 integrated assessment model, which includes the TIMER 2.0 energy model (de Vries et al. 2001) coupled to the climate policy model FAIR-SiMCaP 


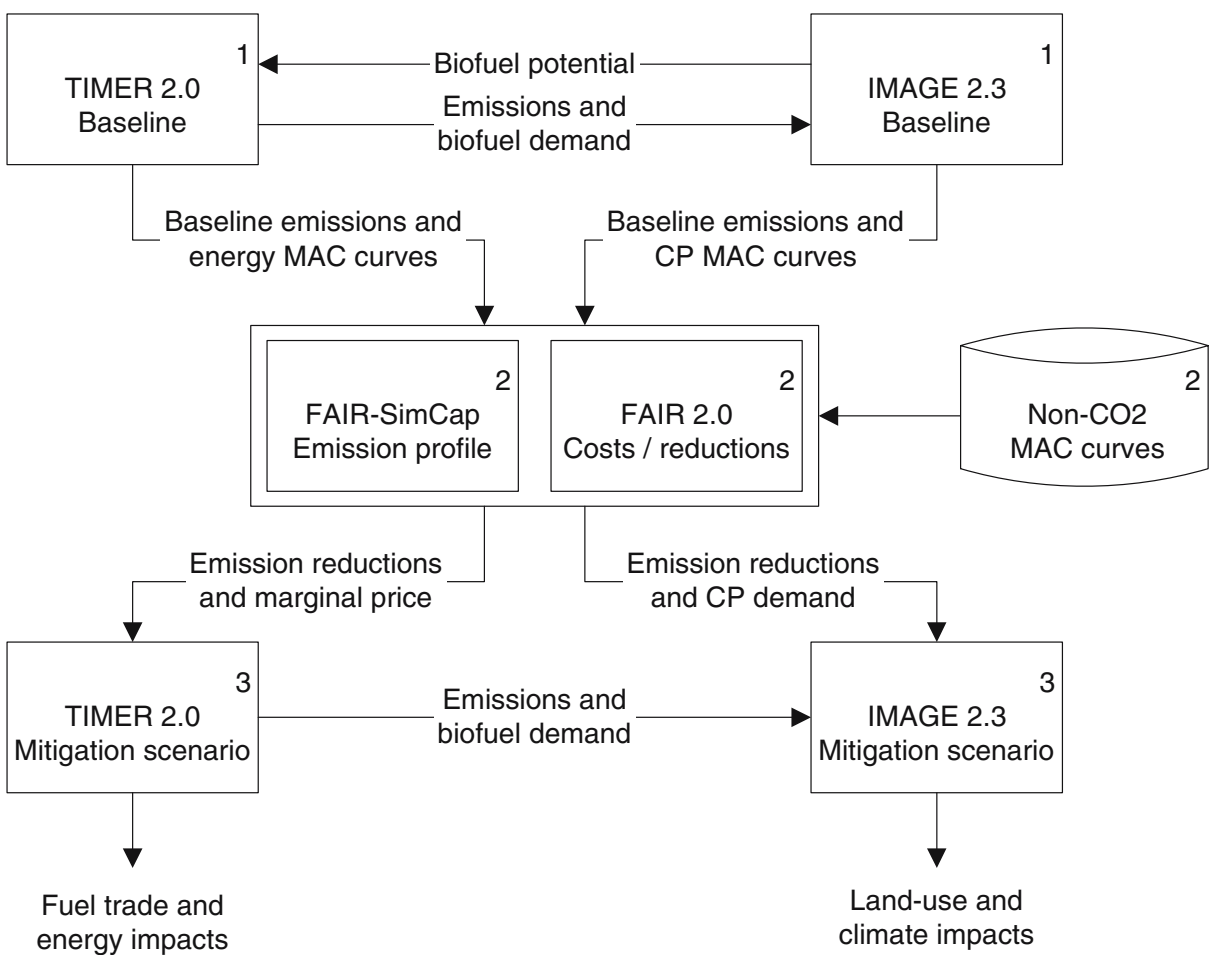

Fig. 1 Linkage and information flows of the applied modelling framework (note $C P$ Carbon plantations). Numbers in figure are explained in the text

(den Elzen and Lucas 2005; den Elzen and Meinshausen 2005). ${ }^{5}$ These models have been linked for the purposes of this analysis in a way similar to that described earlier by van Vuuren et al. (2003), ${ }^{6}$ as shown in Fig. 1. The Appendix provides additional information on the different models used.

The IMAGE 2.3 model is an integrated assessment model consisting of a set of linked and integrated models that together describe important elements of the long-term dynamics of global environmental change, such as air pollution, climate change, and land-use change. IMAGE 2.3 uses a simple climate model and a pattern-scaling method to project climate change at the grid level. At the grid level, agriculture is described by a rule-based system driven by regional production levels. Finally, natural ecosystems are described by an adapted version of the BIOME model. The global energy model, TIMER 2.0, a part of the IMAGE model, describes primary and secondary demand for, and production of, energy and the related emissions of GHG and regional air pollutants. The FAIR-SiMCaP 1.1 model is a combination of the multi-gas abatement-cost model of FAIR 2.1 and the pathfinder module of the SiMCaP 1.0 model. The FAIR cost model distributes the difference between baseline and global emission pathways using a least-cost approach involving regional marginal abatement cost (MAC) curves

\footnotetext{
${ }^{5}$ IMAGE 2.3 is an updated version of IMAGE 2.2 , the difference being the possibility of exploring impacts of bio-energy and carbon plantations. TIMER 2.0 is an updated version of TIMER 1.0. The main differences are additions with respect to hydrogen, bio-energy and modelling of the electric power sector. The FAIRSIMCAP model is the combination of the climate policy support tool FAIR and the SiMCaP model.

${ }^{6}$ In the present framework, FAIR-SIMCAP is used for the calculations of the global emission pathways instead of the IMAGE 2.2 model.
} 
for the different emission sources (den Elzen and Lucas 2005). ${ }^{7}$ The SiMCaP pathfinder module uses an iterative procedure to find multi-gas emission paths that correspond to a predefined climate target (den Elzen and Meinshausen 2005). Calculations in all three main models are done for 17 regions $^{8}$ of the world.

The overall analysis consists of three major steps (Fig. 1):

1. Both the IMAGE and the TIMER model are used to construct a baseline emission scenario. Furthermore, the TIMER model yields the potentials and abatement costs of reducing emissions from energy-related sources, while the IMAGE model provides the potentials and abatement costs associated with carbon plantations.

2. The FAIR-SiMCaP 1.1 model is used to develop global emission pathways that lead to a stabilization of the atmospheric GHG concentration. The concentration calculations are done using the MAGICC 4.1 model that is included in the FAIR-SiMCaP 1.1 model. (Wigley and Raper 2001). The FAIR model distributes the global emission reduction from the baseline across the different regions, gases and sources in a cost-optimal way, using the marginal abatement costs curves. It is assumed that the gases are substituted on the basis of GWPs, an approach consistent with climate policies under the Kyoto Protocol and the USA domestic climate policy (White-House 2002). Furthermore, the model calculates the international permit price, the regional emission reductions, and the global and regional costs of emission reductions.

3. The IMAGE/TIMER model implements the changes in emission levels resulting from the abatement action (emission reductions) and the permit price, as determined in the previous step, to develop the final mitigation scenario (emissions, land use, energy system). Furthermore, the environmental impacts are assessed using the climate model of IMAGE.

In our analysis, we assume that reductions can be distributed across all 17 regions costoptimally from 2013 onwards. This implies the presence of some form of international mechanism that justifies this least-cost assumption, such as emission trading.

\subsection{Baseline emissions}

The baseline scenarios used in this study are based on IPCC-SRES scenarios (Nakicenovic et al. 2000b). This set of baseline scenarios explores different possible pathways for GHG emissions and can roughly be categorized along two dimensions: the degree of globalization vs regionalization, and the degree of orientation towards economic objectives as opposed to an orientation towards social and environmental objectives. In 2001, the IMAGE team published detailed elaborations of these scenarios (IMAGE-team 2001a, b). Although the scenarios are still broadly consistent with the literature, new insights have emerged for some parameters. For instance, population scenarios and economic growth assumptions for low-income regions are now generally lower than assumed in SRES (van Vuuren and O'Neill 2006). Against this background, a set of updated IMAGE scenarios was developed (see Fig. 2). Here, we use the B2 scenario as the main baseline scenario, with the $\mathrm{A} 1 \mathrm{~b}$ and $\mathrm{B} 1$ scenarios being used to show the impacts of different baseline assumptions.

\footnotetext{
${ }^{7}$ Marginal Abatement Cost (MAC) curves reflect the additional costs of reducing the last unit of $\mathrm{CO}_{2}$-eq. emissions.

${ }^{8}$ Canada, USA, OECD-Europe, eastern Europe, the former Soviet Union, Oceania and Japan; Central America, South America, northern Africa, western Africa, eastern Africa, southern Africa, Middle East and Turkey, south Asia (incl. India), South-East Asia and east Asia (incl. China) (IMAGE-team 2001a).
} 

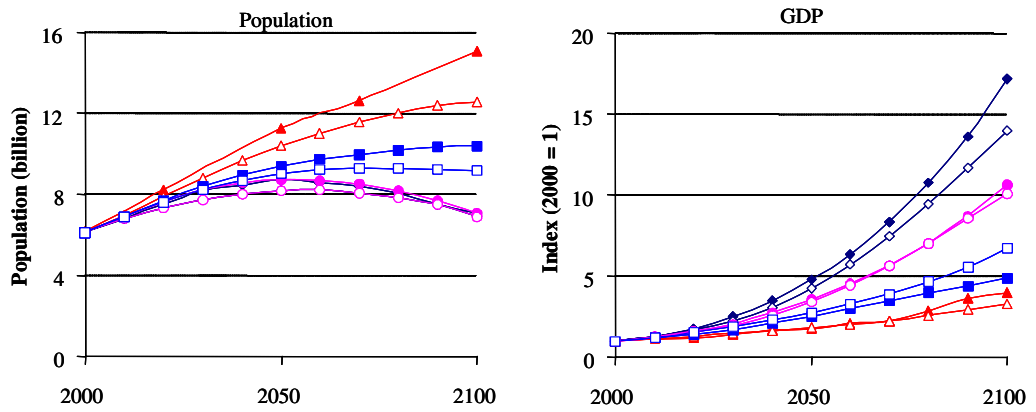

Marker
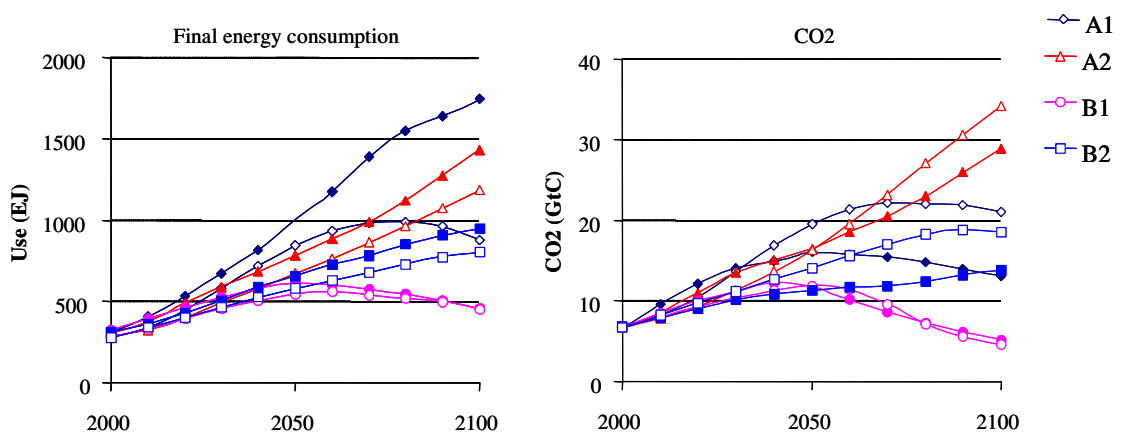

Fig. 2 Driving forces and fossil fuel $\mathrm{CO}_{2}$ emissions of the IMAGE 2.3 SRES scenarios in comparison to the IPCC SRES marker scenarios (Nakicenovic et al. 2000a)

The new implementation of B2 focuses explicitly on exploring the possible trajectory of greenhouse gas emissions on the basis of medium assumptions for the most important drivers (population, economy, technology development and lifestyle). In terms of its quantification, the B2 scenario roughly follows the reference scenario of the World Energy Outlook 2004 for the first 30 years (IEA 2004b). After 2030, economic growth converges to the B2 trajectory of the previous IMAGE scenarios (IMAGE-team 2001a). The long-term UN medium population projection is used for population (UN 2004).

The A1b scenario, by contrast, represents a world with fast economic growth driven by further globalization and rapid technology development. As the scenario that materialintensive lifestyles are adopted globally, energy consumption grows rapidly. The B1 scenario describes a world characterized by strong globalization in combination with environmental protection and a reduction of global inequality. It assumes the use of very efficient technologies, resulting in relatively low energy use. The assumptions for population and economic growth in the A1 and B1 scenarios have been taken from, respectively, the Global Orchestration and Technogarden scenarios of these (MA 2006). In all three scenarios, trends in agricultural production (production levels and yields) are also based on the millennium ecosystem scenarios, which were elaborated for these parameters by the IMPACT model (Rosegrant et al.2002). All other assumptions are based on the earlier implementation of the SRES scenarios.

\subsection{Assumptions in the different subsystems and marginal abatement costs}

We adopt a hybrid approach to determine the abatement efforts among the different categories of abatement options. First, the potential for abatement in different parts of the system 
(energy, carbon plantations, and non- $\mathrm{CO}_{2}$ ) is translated into aggregated baseline- and timedependent MAC curves. These curves are than used in the FAIR model to distribute the mitigation effort among these different categories and to determine the international permit price. The corresponding reduction measures at the more detailed level are determined by implementing the permit price in the different 'expert' models for energy (TIMER) and carbon plantations (IMAGE). For instance, in the case of energy, the TIMER model results in a consistent description of the energy system under the global emission constraint set by FAIR-SiMCaP.

The TIMER, IMAGE and FAIR-SiMCaP models have been linked so that output of one model is the input of the second model (see Fig. 1). In addition, also the model-specific assumptions in the different models have been harmonized. In most cases, this was done on the basis of the storyline of the different scenarios being implemented. For example, technology development is set low for all parameters in the different models in the A2 scenario. The same holds for other driving forces. In terms of land use, both carbon plantations and bio-energy calculations start with the same land-use scenario (implementation factors prevent them using the same land) and the same land price equations. A 5\% per year social discount rate is used to calculate the net present value for the mitigation scenarios. In the energy system, investment decisions are compared using a $10 \%$ per year discount rate, which provides a better reflection of the medium term investment criteria used in making such investments. Table 1 summarizes some of the assumptions made. All costs are expressed in 1995 US\$.

\subsubsection{Energy}

The TIMER MAC curves (used by the FAIR model) are constructed by imposing an emission permit price (carbon tax) and recording the induced reduction of $\mathrm{CO}_{2}$ emissions. ${ }^{9}$ There are several responses in TIMER to adding an emission permit price. In energy supply, options with high carbon emissions (such as coal and oil) become more expensive compared to options with low or zero emissions (such as natural gas, CCS, bio-energy, nuclear power, solar and wind power). The latter therefore gain market share. In energy demand, investments in efficiency become more attractive. The induced reduction of $\mathrm{CO}_{2}$ emissions is recorded for sight-years from 2010 to 2100 (in 10-year steps). Two different permit price profiles were used to explore responses: one that assumes a linear increase from 2010 to the permit price value in the sight year ('linear price MAC') and one that reaches the maximum value 30 years earlier ('block price MAC'). The second profile results in more $\mathrm{CO}_{2}$ reductions because the energy system has more time to respond. Depending on the pathway of the actual permit price in the stabilization scenario, FAIR combines the linear price MAC curves and the block price MAC curves. ${ }^{10}$ In this way, it is possible to take into account (as a first-order approximation) the time pathway of earlier abatement.

In the baseline, stricter investment criteria are used for investments in energy efficiency than for investments in energy supply. Investments in energy efficiency are made only if the apparent average pay-back-time is less than three years (for industry) or two years (other

\footnotetext{
${ }^{9}$ The tax is intended to induce a cost-effective set of measures and is in the model equivalent to a emission permit price. In the rest of the paper, we will use the term (emission) permit price. It should be noted that in reality, the same set of measures as induced by the permit price can also be implement by other type of policies.

${ }^{10}$ FAIR looks 30 years back in time and, by comparing the tax profile in that period to the one assumed in the tax profiles used in TIMER, constructs a linear combination of the two types of response curves. A rapidly increasing tax in FAIR will lead to the use of the linear tax, while a more constant tax level in FAIR will imply the use of the block tax.
} 
Table 1 Default assumptions for various reduction options and the alternative assumptions used in the sensitivity analysis

\begin{tabular}{|c|c|c|c|}
\hline $\begin{array}{l}\text { Mitigation } \\
\text { option }\end{array}$ & Pessimistic assumption & Base case & Optimistic assumption \\
\hline $\begin{array}{l}\text { Carbon } \\
\text { plantations }\end{array}$ & $\begin{array}{l}\text { Carbon uptake reduced by } \\
25 \%+\text { implementation } \\
\text { factor reduced to } 30 \%\end{array}$ & $\begin{array}{l}\text { Implementation factor } 40 \% \\
\text { (i.e., } 40 \% \text { of maximum } \\
\text { potential is used) }\end{array}$ & $\begin{array}{l}\text { Carbon uptake increased } \\
\text { by } 25 \%+\text { implementation } \\
\text { factor increased to } 50 \%\end{array}$ \\
\hline Non- $\mathrm{CO}_{2}$ & $\begin{array}{l}20 \% \text { increase of costs; } \\
20 \% \text { decrease of potential }\end{array}$ & $\begin{array}{l}\text { Expert judgment as } \\
\text { described in Lucas et al. } \\
(2005) \text {. Total reduction } \\
\text { potential of non- } \mathrm{CO}_{2} \\
\text { gases slightly above } 50 \%\end{array}$ & $\begin{array}{l}20 \% \text { decrease of costs; } \\
20 \% \text { increase of potential }\end{array}$ \\
\hline Hydrogen & No hydrogen penetration & $\begin{array}{l}\text { Default assumptions lead to } \\
\text { hydrogen penetration by } \\
\text { the end of the century }\end{array}$ & $\begin{array}{l}\text { Optimistic assumptions for } \\
\text { fuels cells and } \mathrm{H}_{2} \\
\text { production costs }(10 \% \\
\text { reduction of investment } \\
\text { costs) lead to penetration } \\
\text { around } 2050\end{array}$ \\
\hline $\begin{array}{l}\text { Efficiency } \\
\text { improvement }\end{array}$ & $\begin{array}{l}\text { Climate policies do not } \\
\text { lead to removal of } \\
\text { implementation barriers } \\
\text { for efficiency }\end{array}$ & $\begin{array}{l}\text { Climate policies lead to } \\
\text { some removal of } \\
\text { implementation barriers } \\
\text { for efficiency }\end{array}$ & $\begin{array}{l}\text { Climate policies lead to full } \\
\text { removal of implementation } \\
\text { barriers for efficiency }\end{array}$ \\
\hline Bio-energy & $\begin{array}{l}\text { Less available land for } \\
\text { bio-energy }(50 \% \text { less })\end{array}$ & & $\begin{array}{l}\text { Bio-energy can also be } \\
\text { used } \\
\text { in combination with CCS } \\
\text { technology }\end{array}$ \\
\hline $\begin{array}{l}\text { Technology } \\
\text { development }\end{array}$ & $\begin{array}{l}\text { No climate policy-induced } \\
\text { learning }\end{array}$ & $\begin{array}{l}\text { Climate policy-induced } \\
\text { learning }\end{array}$ & \\
\hline $\begin{array}{l}\text { Carbon } \\
\text { capture and } \\
\text { storage }\end{array}$ & $\begin{array}{l}\text { No carbon capture and } \\
\text { storage }\end{array}$ & $\begin{array}{l}\text { Medium estimates for CCS } \\
\text { storage potential (see } \\
\text { Table } 5 \text { ) }\end{array}$ & \\
\hline Nuclear & $\begin{array}{l}\text { Nuclear not available as } \\
\text { mitigation option }\end{array}$ & $\begin{array}{l}\text { Nuclear available as } \\
\text { mitigation option }\end{array}$ & \\
\hline $\begin{array}{l}\text { Emission } \\
\text { trading }\end{array}$ & $\begin{array}{l}\text { Emission trading } \\
\text { restricted due to } \\
\text { transaction costs of } 15 \$ / \mathrm{tC}\end{array}$ & Full emission trading & \\
\hline Land use & $\begin{array}{l}\text { Agricultural yields do not } \\
\text { improve as fast (following } \\
\text { MA's Order from strength } \\
\text { scenario) }\end{array}$ & $\begin{array}{l}\text { Medium yield increases } \\
\text { (following MA's adaptive } \\
\text { mosaic scenario) }\end{array}$ & $\begin{array}{l}\text { Agricultural yields do not } \\
\text { improve as fast (following } \\
\text { MA's global orchestration } \\
\text { scenario) }\end{array}$ \\
\hline Baseline & IMAGE $2.3 \mathrm{~A} 1 \mathrm{~b}$ & IMAGE 2.3 B2 & IMAGE 2.3 B1 \\
\hline All & $\begin{array}{l}\text { All above, excluding land } \\
\text { use and baseline }\end{array}$ & $\begin{array}{l}\text { All above, excluding land } \\
\text { use and baseline }\end{array}$ & $\begin{array}{l}\text { All above, excluding land } \\
\text { use and baseline }\end{array}$ \\
\hline
\end{tabular}

Not for all options both more pessimistic and more optimistic assumptions were tested. 
sectors) (see de Beer 1998). ${ }^{11}$ In low-income countries, we assume that lower efficiency levels are caused by less strict apparent pay-back-time criteria (de Vries et al. 2001). The criteria used in energy supply (based on a $10 \%$ discount rate and the economic life time depending on the type of technology applied) corresponds more-or-less to a pay-back time of six to seven years. The difference between demand and supply investment criteria is based on historical evidence (barriers to demand-side investments include lack of information, more diffuse investors, higher risks and lack of capital). Under climate policies, investments into energy efficiency could therefore form a very cost-effective measure if these barriers can be overcome. In our calculations, we assume that this is partly the case as a result of (1) an increase in attention for ways to reduce carbon emissions (leading to more information) and (2) the availability of capital flows, including flows to developing countries, that could possibly result from carbon trading (or other flexible mechanisms). Based on this, we assume a convergence of the pay-backtime criterion to six years as a function of the existing emission permit price - with full convergence at the highest price considered, i.e., 1,000 US\$/tCeq.

\subsubsection{Carbon plantations}

The MAC curves for carbon plantations have been derived using the IMAGE model (for methodology, see (Graveland et al. 2002; Strengers et al. 2007). In IMAGE, the potential carbon uptake of plantation tree species is estimated for land that is abandoned by agriculture (using a $0.5 \times 0.5$ grid), and compared to carbon uptake by natural vegetation. Only those grid cells are considered in which sequestration by plantations is greater than sequestration by natural vegetation. In the calculations, we assumed that carbon plantations are harvested at regular time intervals, and that the wood is used to meet existing wood demand. Regional carbon sequestration supply curves are constructed on the basis of grid cells that are potentially attractive for carbon plantations. These are converted into MAC curves by adding two kinds of costs: land costs and establishment costs. We found that, under the SRES scenarios, the cumulative abandoned agricultural area ranges from 725 and 940 Mha in 2100 , potentially sequestering 116 to $146 \mathrm{GtC}$ over the century (the term agricultural land in this paper covers both crop and pasture land). The costs of the reductions vary over a wide range.

\subsubsection{Non- $\mathrm{CO}_{2}$ gases}

For non- $\mathrm{CO}_{2}$, the starting point of our analysis consists of the MAC curves provided by EMF-21 (Weyant et al. 2006). This set is based on detailed abatement options, and includes curves for $\mathrm{CH}_{4}$ and $\mathrm{N}_{2} \mathrm{O}$ emissions from energy- and industry-related emissions and from agricultural sources, as well as abatement options for the halocarbons. This set includes MAC curves over a limited cost range of 0 to $200 \mathrm{US} \$ / \mathrm{tC}$-eq., and does not include technological improvements over time. Lucas et al. (in press) have extended this set on the basis of a literature survey and expert judgement about long-term abatement potential and costs (see also van Vuuren et al. 2006b). The long-term potential is significantly higher than current potential as a result of technology development and the removal of

\footnotetext{
${ }^{11}$ A pay-back-time is a simple investment criterion that indicates the time-period required to earn back the original investment. Research indicates that many actors are not aware of the energy efficiency improvement measures that are available to them that have shorter pay-back-time periods than their official criterion. As a result, the average apparent pay-back-time of a sector is considerably lower than the investment criteria that are stated to be used by these actors (de Beer 1998).
} 
implementation barriers. The overall potential amounts to about $3 \mathrm{GtC}$-eq. annually (with the lion's share available below 200 US\$/tC-eq.).

\subsection{Emission pathways}

This study uses a set of global multi-gas emission pathways that meet GHG concentration stabilization targets at 450, 550 and $650 \mathrm{ppm} \mathrm{CO}_{2}$-eq. (den Elzen and Meinshausen 2005). These pathways are assumed to be technically feasible, as we calculated them using the MAC curves discussed above. In general terms, three main criteria were used when developing the pathways. First, a maximum reduction rate was assumed reflecting the technical (and political) inertia that limits emission reductions. Fast reduction rates would require the early replacement of existing fossil-fuel-based capital stock, and this may involve high costs. Secondly, the reduction rates compared to baseline were spread out over time as far as possible - but avoiding rapid early reduction rates and, thirdly, the reduction rates were only allowed to change slowly over time. The selected values are based on the reduction rates of the post-SRES mitigation scenarios (e.g., Swart et al. 2002) and the lower range of published mitigation scenarios (Azar et al. 2006; Nakicenovic and Riahi 2003). In the case of the 650 and 550 ppm $\mathrm{CO}_{2}$-eq. pathways, the resulting pathway leads to stabilization below the target level and without overshoot between 2100 and 2200. For the $450 \mathrm{ppm} \mathrm{CO}_{2}$-eq. concentration target, however, a certain overshoot (or peaking) is assumed: concentrations may first increase to $510 \mathrm{ppm}$ before stabilizing at $450 \mathrm{ppm} \mathrm{CO}_{2}$-eq. before 2200. This overshoot is justified by reference to present concentration levels, which are already substantial, and the attempt to avoid drastic sudden reductions in the emission pathways presented.

\section{Stabilizing GHG concentration at $650,550,450 \mathrm{ppm}$ : central scenarios}

\subsection{Emission pathways and reductions}

Under the central baseline, B2, worldwide primary energy use nearly doubles between 2000 and 2050 and increases by another $35 \%$ between 2050 and 2100. Most of this growth occurs in non-annex I regions (about $80 \%$ ). Oil continues to be the most important energy carrier in the first half of the century, with demand being mainly driven by the transport sector. Natural gas dominates new capacity in electric power in the first decades, but starts to be replaced by coal from 2030 onwards due to increasing gas prices. As a result, coal becomes the dominant energy carrier in the second half of the twenty-first century. Energy-sector $\mathrm{CO}_{2}$ emissions continue to rise for most of the century, peaking at $18 \mathrm{GtC}$ in 2080 . Total GHG emissions $^{12}$ also increase, i.e., from about $10 \mathrm{GtC}$-eq. today to $23 \mathrm{GtC}$-eq. in 2100 (Fig. 3). Figure 3 also shows that compared to existing scenario literature; this baseline is a medium-high emission baseline. As a result of decreasing deforestation rates, $\mathrm{CO}_{2}$ emissions from land use decrease. At the same time, $\mathrm{CH}_{4}$ emissions, mostly from agriculture, increase. The GHG concentration reaches a level of $925 \mathrm{ppm} \mathrm{CO}_{2}$-eq., leading to an increase in the global mean temperature of $3{ }^{\circ} \mathrm{C}$ in 2100 (for a climate sensitivity of $2.5^{\circ} \mathrm{C}$ ).

Figure $3 \mathrm{a}$ shows that, in order to reach the selected emission pathway that leads to stabilization of GHG radiative forcing at 650,550 and 450 ppm $\mathrm{CO}_{2}$-eq., $\mathrm{GHG}$ emissions need to be reduced in 2100 by respectively $65 \%, 80 \%$ and $90 \%$ compared to the B2 baseline.

\footnotetext{
${ }^{12}$ The term total GHG emissions in this report refers to all GHG covered by the Kyoto protocol: i.e., $\mathrm{CO}_{2}$, $\mathrm{CH}_{4}, \mathrm{~N}_{2} \mathrm{O}, \mathrm{HFCs}$, PFCs and $\mathrm{SF}_{6}$.
} 

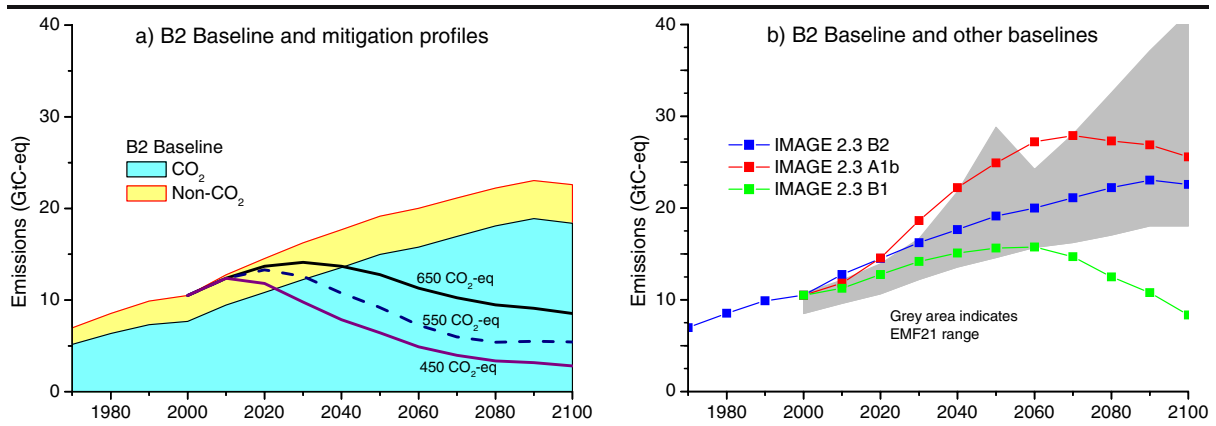

Fig. 3 Global $\mathrm{CO}_{2}$-eq. emissions (all sources $)_{2}$ ) for the $\mathrm{B} 2$ baseline emission and pathways to stabilization at a concentration of 650,550 and $450 \mathrm{ppm} \mathrm{CO}_{2}$-eq. (a, left) and the $\mathrm{B} 2$ baseline emissions compared to alternative baselines (b, right), sources: for the EMF-21 scenarios (van Vuuren et al. 2006c; Waterloo et al. 2001)

The short-term differences are even more significant: In the case of the $650 \mathrm{ppm} \mathrm{CO}_{2}$-eq. pathway, emissions can still increase slightly and stabilize at a level that is $40 \%$ above current emissions in the next three to four decades, followed by a slow decrease. In the case of the $550 \mathrm{ppm} \mathrm{CO}_{2}$-eq. pathway, however, global emissions need to peak around 2020, directly followed by steep reductions in order to avoid overshooting the $550 \mathrm{ppm} \mathrm{CO}_{2}$-eq. concentration level. For stabilization at $450 \mathrm{ppm} \mathrm{CO}_{2}$-eq., short-term reductions become even more stringent, with global emissions peaking around 2020 at a level of $20 \%$ above 2000 levels.

\subsection{Abatement action in the stabilization scenarios}

\subsubsection{Abatement across different gases}

Figure 4 shows the (cost-optimal) reduction in the mitigation scenarios in terms of different gases (upper panel). Table 2, in addition, indicates the emission levels. In the short term, in all stabilization scenarios, a substantial share of the reduction is achieved by reducing non- $\mathrm{CO}_{2}$ gases while only $10 \%$ of the reductions come from reducing energy-related $\mathrm{CO}_{2}$ emissions (see also Lucas et al. 2005). The disproportionate contribution of non- $\mathrm{CO}_{2}$ abatement is caused mainly by relatively low-cost abatement options that have been identified for non- $\mathrm{CO}_{2}$ gases (e.g., reducing $\mathrm{CH}_{4}$ emissions from energy production and $\mathrm{N}_{2} \mathrm{O}$ emissions from adipic and acidic acid industries). It should be noted that this is related to the fact that we use GWPs to determine the cost-effective mix of reductions among the different GHGs (see Section 3). Alternative approaches, e.g., long-term costs optimization under a radiative forcing target, may result to a different mix (van Vuuren et al. 2006c). After 2015, more and more reductions will need to come from $\mathrm{CO}_{2}$ in the energy system, increasing to $85 \%$ by 2100. This shift simply reflects that non- $\mathrm{CO}_{2}$ represents about $20 \%$ of total GHG emissions and the limited reduction potential for some of the non- $\mathrm{CO}_{2}$ gases. In addition, some non$\mathrm{CO}_{2}$ GHGs cannot be reduced fully due to limited reduction potential (this is the case for some sources of land-use-related $\mathrm{CH}_{4}$ but is particularly true for some of the $\mathrm{N}_{2} \mathrm{O}$ emission sources, see below). The proportion of non- $\mathrm{CO}_{2}$ abatement does decline somewhat further in the $450 \mathrm{ppm} \mathrm{CO}$-eq. scenario than in the $650 \mathrm{ppm} \mathrm{CO} \mathrm{CO}_{2}$-eq. scenario (with the proportion being limited by the absolute non- $\mathrm{CO}_{2}$ reduction potential).

More detailed analysis across the different sources shows that, for $\mathrm{CH}_{4}$, relatively large reductions are achieved in the areas of landfills and the production of coal, oil and gas. 


\section{0 ppm $\mathrm{CO}_{2}$-eq.}
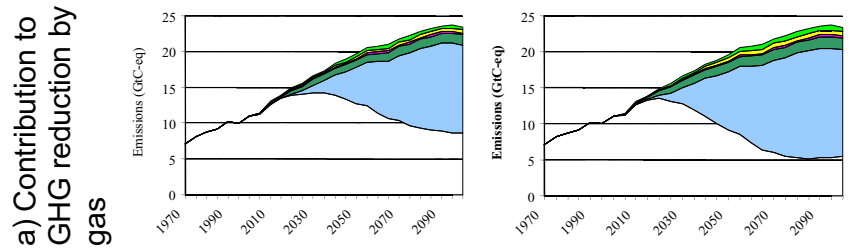

550 ppm $\mathrm{CO}_{2}$-eq.
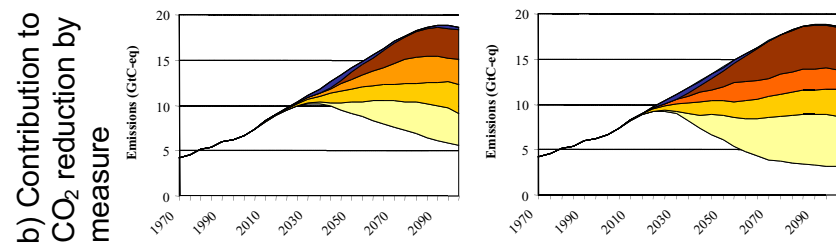

a) Contribution to GHG
reduction by gas

$\square$ Carbon plantations

$\square$ F-gasses

b) Contribution to $\mathrm{CO}_{2}$ reduction by measure

$\square \mathrm{N} 2 \mathrm{O}$

$\square \mathrm{CH} 4$

$\square \mathrm{CO} 2$
450 ppm $\mathrm{CO}_{2}$-eq.


$\square$ Fuel switch

$\square \mathrm{CCS}$

$\square$ Biofuels

$\square$ Nuclear, solar \& wind power

$\square$ Efficiency improvement

Fig. 4 Emission reductions for total GHG emissions contributed by gas (upper panel; a) and for energy $\mathrm{CO}_{2}$ emissions contribute by reduction measure category (lower panel; b) applied to stabilization scenarios at 650 , 550 and $450 \mathrm{ppm} \mathrm{CO}_{2}$-eq

In total, under the $450 \mathrm{ppm} \mathrm{CO}_{2}$-eq. stabilization scenario, emissions are reduced by $70 \%$ compared to the baseline. In the less stringent $650 \mathrm{ppm}$ stabilization case, $\mathrm{CH}_{4}$ emissions are halved (returning roughly to today's levels). In the case $\mathrm{N}_{2} \mathrm{O}$, substantial reductions are achieved for acidic and adipic acid production (up to $70 \%$ reduction). However, in comparison to land-use related $\mathrm{N}_{2} \mathrm{O}$ emissions, this only represents a small source. For the

Table 2 Emissions in 2000 and in 2100 for the B2 baseline and the stabilization scenarios

\begin{tabular}{|c|c|c|c|c|c|}
\hline & \multirow[t]{3}{*}{2000} & \multicolumn{4}{|l|}{2100} \\
\hline & & \multirow[t]{2}{*}{ Baseline } & \multicolumn{3}{|c|}{ Stabilization scenarios (ppm $\mathrm{CO}_{2}$-eq.) } \\
\hline & & & 650 & 550 & 450 \\
\hline & \multicolumn{5}{|l|}{ GtC-eq. } \\
\hline \multicolumn{6}{|l|}{$\mathrm{CO}_{2}$ energy/industry } \\
\hline Electricity sector & 2.38 & 7.96 & 1.04 & 0.23 & 0.09 \\
\hline Industry & 0.62 & 1.54 & 0.38 & 0.18 & 0.03 \\
\hline Buildings & 0.50 & 0.80 & 0.32 & 0.23 & 0.06 \\
\hline Transport & 0.79 & 2.48 & 0.69 & 0.32 & 0.03 \\
\hline Other & 0.79 & 2.11 & 0.82 & 0.40 & 0.15 \\
\hline Total & 6.96 & 18.40 & 5.20 & 2.50 & 0.94 \\
\hline $\mathrm{CO}_{2}$ land use & 0.90 & 0.10 & 0.75 & 0.67 & 0.77 \\
\hline $\mathrm{CH}_{4}$ & 1.88 & 3.02 & 1.33 & 1.11 & 0.91 \\
\hline $\mathrm{N}_{2} \mathrm{O}$ & 0.68 & 1.03 & 0.81 & 0.78 & 0.69 \\
\hline F-gases & 0.14 & 0.87 & 0.35 & 0.27 & 0.04 \\
\hline Total & 10.56 & 23.42 & 8.44 & 5.33 & 3.35 \\
\hline
\end{tabular}




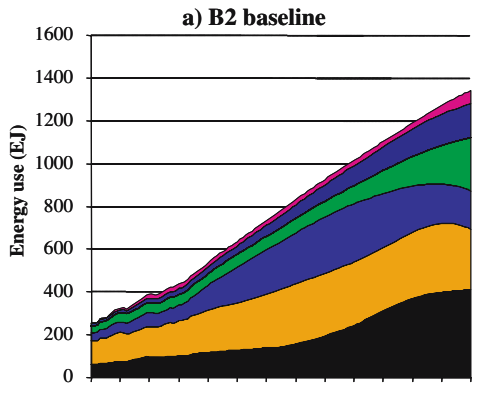

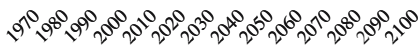

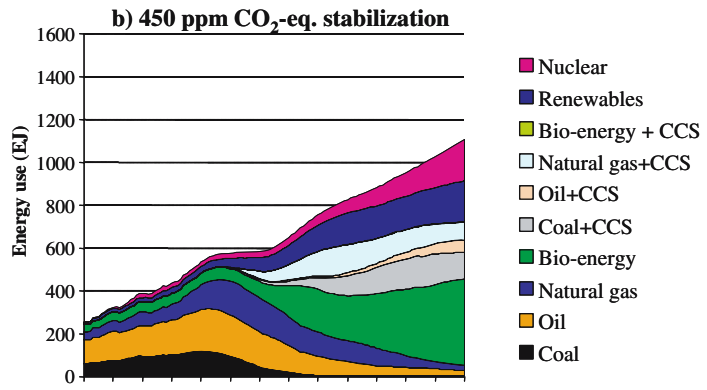

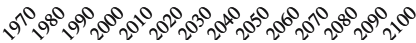

Fig. 5 Primary energy use in the $\mathrm{B} 2$ baseline (left, a) and the $450 \mathrm{ppm} \mathrm{CO}_{2}$-eq. stabilization scenario (right, b). Note: Nuclear, solar, wind and hydro power have been reported at a virtual efficiency of $40 \%$; 'bioenergy' includes traditional biofuels; renewables include hydro, solar and wind power

land-use-related $\mathrm{N}_{2} \mathrm{O}$ sources, emission reduction rates are smaller. As a result, total $\mathrm{N}_{2} \mathrm{O}$ emission reductions in the most stringent scenario amount to about $35 \%$ compared to baseline. In the most stringent case, emissions of halocarbons are reduced to almost zero for the group as a whole. In the other two scenarios, considerable reduction rates are still achieved.

The use of carbon plantations contributes about $0.9 \mathrm{GtC}$ annually to the overall mitigation objective in 2100 in the $450 \mathrm{ppm} \mathrm{CO}_{2}$-eq. scenario but less in the other two scenarios (0.5 and $0.25 \mathrm{GtC}$ annually). In all three scenarios, East Asia, South America and the former Soviet Union together account for more than $50 \%$ of the carbon plantation mitigation effort (regional detail is not shown in figures - but can be found in Strengers et al. (2007). The trees used vary according to the location and include Populus Nigra (East Asia and Europe), Picea Abies (Canada, USA and former USSR) and E. Grandis (South America, central Africa and Indonesia). In all three scenarios, high sequestration rates (more than 0.1 GtC annually) are achieved only after 2030-2035 due to limited land availability early on. Some of the mitigation by carbon plantations can be achieved at relatively low-costs - and form a substantial part of the potential used in the $650 \mathrm{ppm}$ $\mathrm{CO}_{2}$-eq. stabilization scenario. The potential of carbon plantations does depend more on external assumptions (e.g., the implementation fraction) than on the stabilization target.

\subsubsection{Abatement action in the energy system}

Figure 5 shows that the climate policies required to reach the stabilization pathways lead to substantial changes in the energy system compared to the baseline scenario (shown for $450 \mathrm{ppm} \mathrm{CO}_{2}$-eq.). These changes are more profound when going from 650 to $450 \mathrm{ppm}$ $\mathrm{CO}_{2}$-eq. In the most stringent scenario, global primary energy use is reduced by around $20 \%$. Clearly, the reductions are not similar for the different energy carriers. The largest reductions occur for coal, with the remaining coal consumption being primarily used in electric power stations using CCS. There is also a substantial reduction for oil. Reductions for natural gas are less substantial, while other energy carriers - in particular solar, wind and nuclear-based electricity and modern biomass - gain market share. ${ }^{13}$

The largest reduction in the energy sector results from changes in the energy supply (Fig. 4; lower panel). Some changes stand out. First of all, under our default assumptions,

\footnotetext{
${ }^{13}$ Modern biomass includes gaseous or liquid fuels produced from plants or trees. It differs from traditional biomass (gathered wood, straw, dung, charcoal, etc).
} 
CCS - mainly in the power sector - accounts for a major proportion of the emission reductions (up to a third of the reductions in energy-related $\mathrm{CO}_{2}$ emissions). As a result, large amounts of $\mathrm{CO}_{2}$ are stored. In the $650 \mathrm{ppm}$ case, $160 \mathrm{GtC}$, or about $2 \mathrm{GtC}$ annually on average, needs to be stored, mainly in empty gas and oil fields. In the 550 and 450 cases, these numbers are 250 and $300 \mathrm{GtC}$, or about $3 \mathrm{GtC}$ annually. Here, we use medium estimates of storage capacity (around 1,000 GtC) but estimates in the low range are in the order of $100 \mathrm{GtC}$ (Hendricks et al. 2002). In the more densely populated regions, we find that under our medium assumptions reservoirs from depleted fossil fuel resources will be filled near the end of the century so that these regions will also use aquifers as a storage option. ${ }^{14}$ The decreasing reservoir capacity will lead to slightly higher costs. It should be noted that CCS technology still has to be proven in large scale application - and aquifer capacity is uncertain.

Bio-energy use also accounts for a large proportion of the emission reductions. In the baseline scenario of this study about 200 EJ of bio-energy are used. In the most stringent stabilization scenario, bio-energy use increases to 350 EJ. In terms of crops, the bio-energy is produced from a mixture of crops (sugar cane, maize and woody bio-energy depending on the region). The use of bio-energy requires land where, in the baseline, there would be regrowing natural vegetation sequestering carbon. The decrease in carbon sequestration by bio-energy production compared to natural vegetation regrowth amounts to about $1-5 \mathrm{~kg} \mathrm{C}$ per GJ of bio-energy produced, depending on the region and biome (this number represents the annual average across the whole scenario period, by taking the cumulative bio-energy production and the cumulative difference in carbon uptake between the land used for bioenergy production and the original vegetation). This compares to standard emission factors of $25 \mathrm{~kg} \mathrm{C}$ per GJ for coal, $20 \mathrm{~kg} \mathrm{C}$ per GJ for oil and $15 \mathrm{~kg} \mathrm{C}$ per GJ for natural gas. The contribution shown in Fig. 4 indicates the net contribution.

Solar, wind and nuclear power also account for a considerable proportion of the required reductions. In our baseline scenario, the application of renewables (i.e., hydro, wind and solar power) is considerably larger than that of nuclear power (based on current policies and costs). In the mitigation scenario both categories increase their market share. For hydropower, we assumed no response to climate policy (given the fact that in the baseline most regions are already approaching their maximum potential levels - and investments into hydropower are often related to other objectives than energy alone). As a result of their intermittent character, the contribution of solar and wind power is somewhat limited by a declining ability to contribute to a sufficiently reliable electric power system at high penetration rates. As a result, in the model the increase in nuclear power compared to the baseline is larger than that of renewables. The finding that under climate policy, nuclear power could become a competitive option to produce electric power is consistent with several other studies (MIT 2003; Sims et al. 2003). However, more flexible power systems, different assumptions on the consequences of intermittency for renewables, the development of storage systems, technological breakthroughs or taking account of public acceptance of nuclear power could easily lead to a different mix of nuclear power, solar and wind power and CCS technologies (and still lead to a similar reduction rate).

Energy efficiency represents a relatively important part of the portfolio early on in the century - but a much smaller share compared to baseline later on. The main reason for the

\footnotetext{
${ }^{14}$ In our analysis we have used the reservoir estimates as estimated by Hendriks et al. (2002), including their estimates for aquifers. Hendriks et al. (2002) restricted the potentially available storage capacity in aquifers severely based on safety requirements for storage. Still, one might argue that the reservoir estimates for aquifers are more uncertain as those for (empty) fossil fuel reservoirs.
} 
decreasing impact is that costs reductions of zero carbon energy supply options reduces the effectiveness of energy efficiency measures. In addition, the fact that energy efficiency will be closer to the technology frontier in many parts of world will slow down further improvement. Globally, energy use is reduced in 2100 by about $10 \%$ in the $650 \mathrm{ppm}$ case and about $20 \%$ in the $450 \mathrm{ppm}$ case. The contribution of efficiency does vary strongly by region and over time. In western Europe, for instance, in the model the annual rate of real efficiency improvement in the baseline is about $1.1 \%$ per year in the first half of the century, and $0.8 \%$ per year over the century as a whole (these numbers refer to the underlying efficiency indicators in the model; not the energy intensity (energy over GDP) that improves somewhat faster due to structural change). The increased energy prices under climate policies in combination with the reduction of investment barriers could raise the numbers to $1.5 \%$ and $1.0 \%$ per year respectively in the $450 \mathrm{ppm} \mathrm{CO}_{2}$-eq. scenario. In India, climate policy could have a much larger impact. Here, baseline efficiency improvement is assessed at $2.2 \%$ per year in the first 40 years and $1.8 \%$ per year over the century. Climate policies could push up these numbers to $2.9 \%$ and $2.1 \%$ per year respectively.

An alternative way to look at these data is to use the Kaya indicators of energy intensity $(\mathrm{GJ} / \$)$ and the carbon factor (kg C/GJ) (Kaya 1989). Under the baseline scenario, energy intensity improves significantly by about $70 \%$ worldwide between 2000 and 2100 . The carbon factor remains virtually constant (in line with historic trends). It is only in the last decades that some decarbonization occurs as high oil prices induce a transition to bio-energy. This implies that, in the baseline scenario, energy intensity improvement is the main contributor to decreasing the ratio between $\mathrm{CO}_{2}$ emissions and GDP growth ( $\left.\mathrm{kg} \mathrm{C} / \mathrm{GDP}\right)$. In the mitigation scenarios, the rates increase for both energy intensity and carbon factor improvement. While the contribution of the two factors to emission reductions compared to baseline levels is about the same in 2020 (this can be seen in Fig. 6 since the mitigation scenario 2020 points are moved parallel to the diagonal in the figure compared to the baseline scenario points), changes in the carbon factor compared to baseline (in other words: changes in energy supply) in 2050 and 2100 contribute much more to lower emission levels than energy intensity. Under the $450 \mathrm{ppm}$ scenario, the carbon factor decreases by about $85 \%$ compared to baseline by the end of the century.

\subsection{Costs}

\subsubsection{Abatement costs}

As costs measures, we will focus on marginal permit prices and abatement costs. The latter are calculated on the basis of the marginal permit prices and represent the direct additional costs due to climate policy, but do not capture macro-economic costs (nor the avoided damages of climate change). Figure 7 shows that the scenarios involving stabilization at 650 and $550 \mathrm{ppm} \mathrm{CO}_{2}$-eq. ppm are characterized by a rather smooth increase in the marginal price followed by a drop by the end of the century. The latter is caused by a fall in emissions in the baseline and further cost reductions in mitigation technologies (in particular, hydrogen fuel cells start entering the market by this time, allowing for reductions in the transport sector at much lower costs). For the $450 \mathrm{ppm}$ stabilization scenario, the marginal price rises steeply during the first part of the century - reaching a marginal price of over 600 US\$/tC-eq. by 2050 - and finally stabilizes at $800 \mathrm{US} \$ / \mathrm{tC}$-eq. by the end of the century. The high marginal price is particularly necessary to reduce emissions from the more nonresponsive sources such as $\mathrm{CO}_{2}$ emissions from transport or some of the non- $\mathrm{CO}_{2}$ emis- 


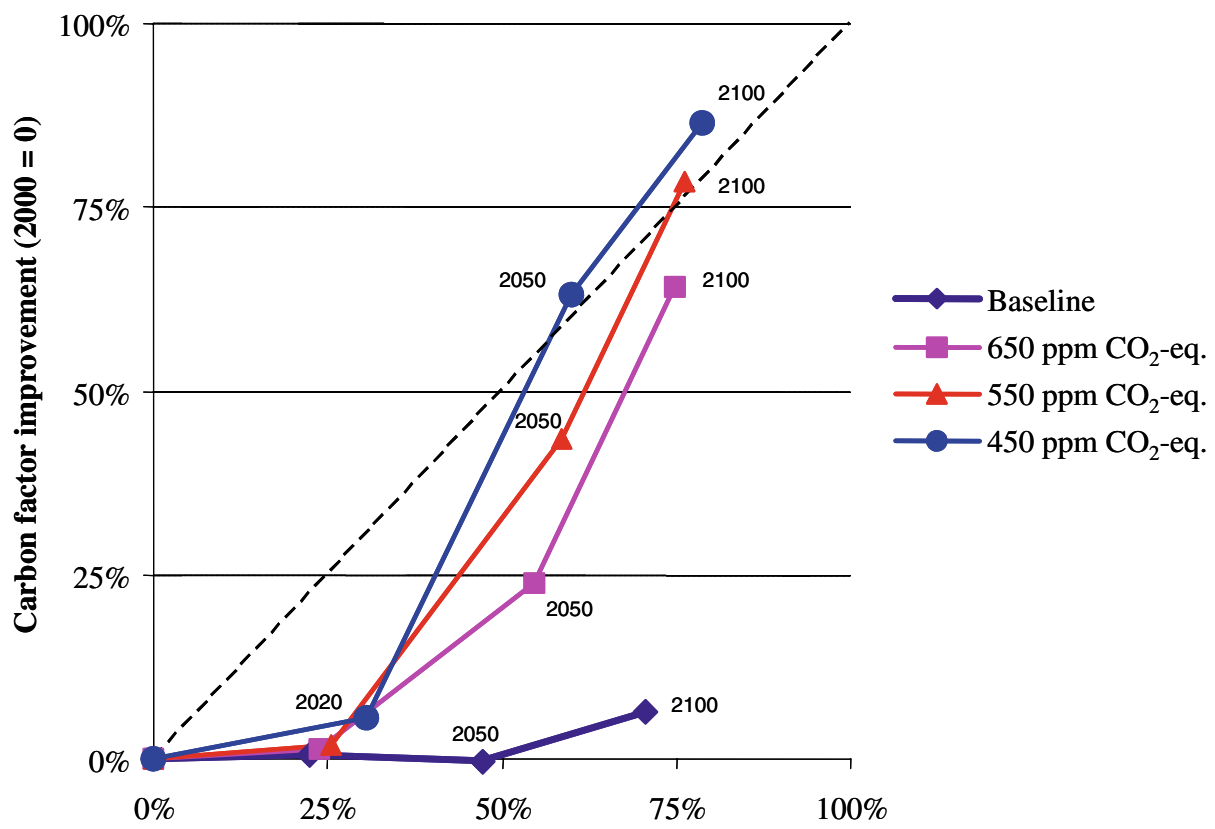

Energy intensity improvement $(2000=0)$

Fig. 6 Relative changes in global energy intensity (energy/GDP) and the carbon factor $\left(\mathrm{CO}_{2} /\right.$ energy) in the B2 baseline and the three mitigation cases compared to 2000 values. Note: The diagonal line indicates equal reduction in the energy intensity and carbon factor compared to 2000. Values are indicated for all the scenarios: 2020, 2050 and 2100. The ovals indicate the outcomes of the mitigation cases for similar years

sions from agricultural sources, while other sources, such as electric power, already reduce their emissions to virtually zero at a permit prices of 'only' 200-300 US\$/tC-eq.

Costs can also be expressed as abatement costs as a percentage of GDP. This indicator is shown over time (Fig. 7; right panel), and accumulated across the century (net present value; discounted at 5\%; Fig. 8). In the $650 \mathrm{ppm} \mathrm{CO}_{2}$-eq. stabilization scenario, costs first

a) Marginal permit price

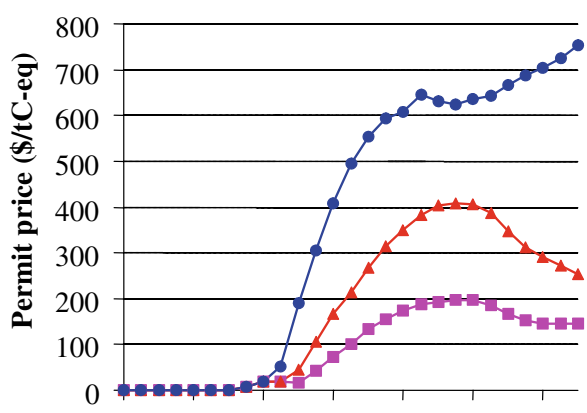

1970199020102030205020702090 b) Abatement costs

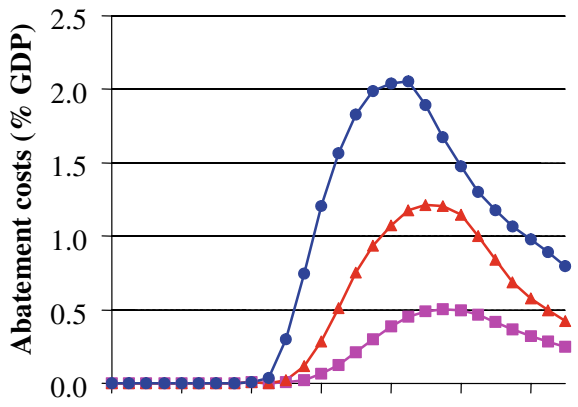

1970199020102030205020702090

$-650 \mathrm{ppm} \mathrm{CO}_{2}$-eq $\quad \leftarrow 550 \mathrm{ppm} \mathrm{CO}_{2}$-eq $\rightarrow 450 \mathrm{ppm} \mathrm{CO}_{2}$-eq

Fig. 7 Marginal carbon-equivalent price for stabilizing greenhouse gas concentration at 650,550 and $450 \mathrm{ppm}$ $\mathrm{CO}_{2}$-eq. from the $\mathrm{B} 2$ baseline (left; a) and abatement costs as a percentage of GDP for these scenarios (right; b) 
increase to about $0.5 \%$ of GDP, after which they decline slightly to about $0.3 \%$ of GDP. This reduction is caused by an increase in global GDP and stabilizing climate costs due to a somewhat lower permit price and a stabilizing emission gap between baseline and the mitigation scenario. The same trend is observed for the other stabilization scenarios, although at higher costs. The abatement costs of the $550 \mathrm{ppm} \mathrm{CO}_{2}$-eq. stabilization scenario increase to $1.2 \%$ of GDP, while the abatement costs of the $450 \mathrm{ppm} \mathrm{CO}_{2}$-eq. stabilization scenario increase to $2.0 \%$ of global GDP. The direct abatement costs of about $0 \%-2.5 \%$ of GDP can be compared to the total expenditures of the energy sector (which, worldwide, are about $7.5 \%$ of GDP today and expected to remain nearly constant under our baseline) or to the expenditures on environmental policy (in the EU around $2.0 \%-2.8 \%$, mostly for waste and wastewater management).

The net present value of the abatement costs follow a similar trend (across the different stabilization levels) as described above for the costs over time (Fig. 8). For default baseline (B2), the costs vary from $0.2 \%$ of GDP for stabilization at $650 \mathrm{ppm}$ to $1.1 \%$ of GDP in the 450 case.

\subsubsection{Changes in fuel trade patterns}

Figure 9 shows the imports and exports of different fuels in 2050. The clearest differences are found in the oil and coal trades, which are greatly reduced as a result of lower consumption levels. On the one hand, oil-exporting regions will see their exports reduced by a factor of about $2-3$. On the other hand, the oil imports of importing countries are significantly reduced. Interestingly, natural gas trade is hardly affected because natural gas can be used very effectively in combination with CCS. An interesting area is the role played by the bio-energy trade. This trade increases substantially and major exporting regions (including, for instance, South America and the former Soviet Union) could benefit from this. Currently, oil-importing regions (such as the USA, western Europe and Asia) could become major bio-energy importing regions.

Fig. 8 Net present value (NPV) of abatement costs for different stabilization levels as percentage of the NPV of GDP, starting from different baseline scenarios (discount rate $5 \%$ )

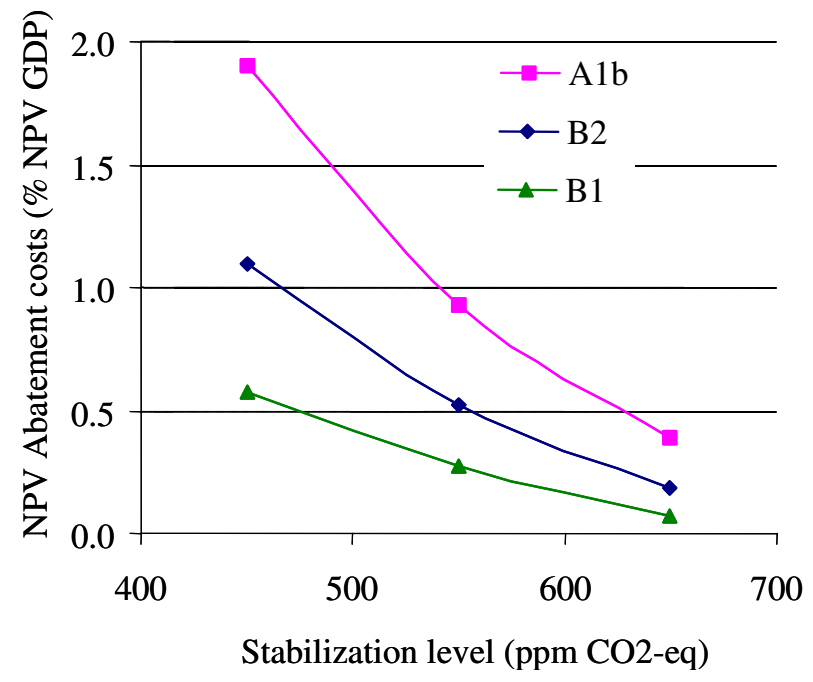

Springer 




Fig. 9 World volume of fuel trade between the 17 world regions (EJ); 2000, Baseline (B2) and stabilization scenarios $\left(650,550\right.$ and 450 ppm $\mathrm{CO}_{2}$-eq)

\section{Benefits and co-benefits}

\subsection{Climate benefits of stabilization}

The three multi-gas stabilization scenarios analyzed here lead to clearly different temperature increases, both during this century and in the long run. Table 3 shows some of the parameters, describing the different scenarios in more detail and using a single value for climate sensitivity $\left(2.5^{\circ} \mathrm{C}\right)$. The table shows that, in 2100 , the 650 and $550 \mathrm{ppm} \mathrm{CO}_{2}$-eq. stabilization scenarios are still approaching the stabilization levels, while the $450 \mathrm{ppm}$ $\mathrm{CO}_{2}$-eq. scenario has in fact overshot its target (as designed) and is approaching its target from a higher concentration level (the $2100 \mathrm{CO}_{2}$-eq. concentration is $479 \mathrm{ppm}$ ). For $\mathrm{CO}_{2}$ only, our three scenarios generate $\mathrm{CO}_{2}$ concentrations of 524, 463 and 424 ppm for 2100 and this is indeed on the lower side of existing $\mathrm{CO}_{2}$-only stabilization scenarios in the literature.

It should be noted, however, that the temperature results of the different stabilization scenarios depend to a considerable extent on the uncertain relationship between the GHG concentration and temperature increase. This implies that impacts on temperature can better be expressed in probabilistic terms. Figure 10 shows, on the basis of the work of Meinshausen (2006), the probabilities of overshooting a $2{ }^{\circ} \mathrm{C}$ and a $2.5^{\circ} \mathrm{C}$ target in the light of the

Table 3 Overview of several key parameters for the stabilization scenarios explored

\begin{tabular}{|c|c|c|c|c|c|}
\hline & \multicolumn{2}{|c|}{$\begin{array}{l}2100 \text { concentration } \\
(\mathrm{ppm})\end{array}$} & \multirow{2}{*}{$\begin{array}{l}\text { Reduction of cumulative } \\
\text { emissions in 2000-2100 } \\
\text { period } \\
\%\end{array}$} & \multicolumn{2}{|c|}{$\begin{array}{l}\text { Temperature change } \\
\left.{ }^{\circ} \mathrm{C}\right)\end{array}$} \\
\hline & $\mathrm{CO}_{2}$-eq. & $\mathrm{CO}_{2}$ & & 2100 & Equilibrium \\
\hline B2 & 947 & 708 & 0 & 3.0 & - \\
\hline B2 650 ppm $\mathrm{CO}_{2}$-eq. & 625 & 524 & 36 & 2.3 & 2.9 \\
\hline B2 550 ppm $\mathrm{CO}_{2}$-eq. & 538 & 463 & 50 & 2.0 & 2.5 \\
\hline B2 450 ppm $\mathrm{CO}_{2}$-eq. & 479 & 424 & 61 & 1.7 & 2.0 \\
\hline
\end{tabular}



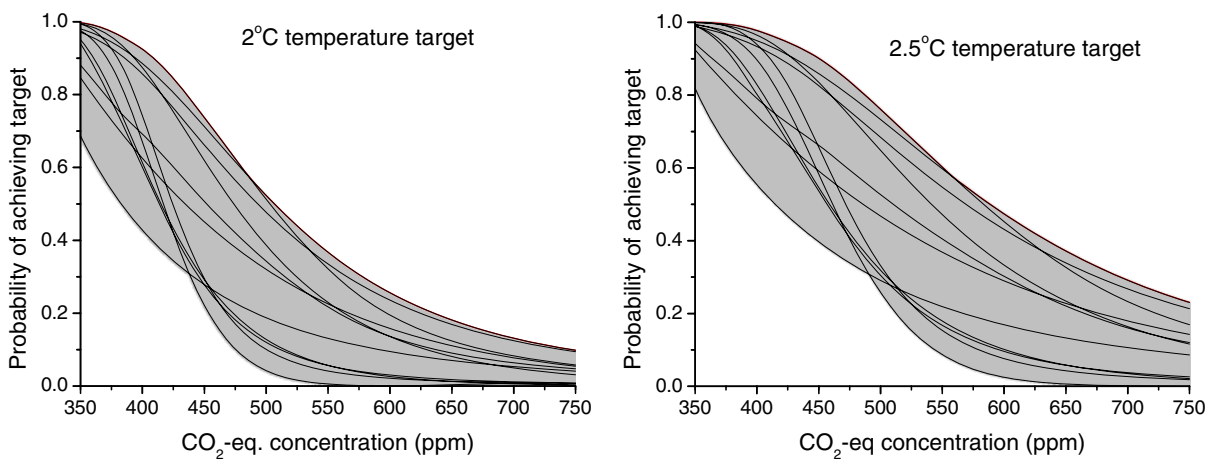

Fig. 10 Probability of equilibrium temperature change staying within the 2 or $2.5^{\circ} \mathrm{C}$ limit for compared to pre-industrial for different $\mathrm{CO}_{2}$-eq. concentration levels compared to pre-industrial (following calculations of (Meinshausen 2006). Note: The lines indicate the probability function as indicated in the individual studies quoted by (Meinshausen 2006); the grey area indicates the total range between the highest and lowest study

different stabilization levels explored in this paper (the corridor shown is a result of the fact that Meinshausen considered several PDFs published in the literature). In the case of a $2{ }^{\circ} \mathrm{C}$ target, the $650 \mathrm{ppm}$ scenario gives a probability of meeting this target between $0 \%-18 \%$ depending on the PDF used. By contrast, the $450 \mathrm{ppm}$ scenarios result in a probability range of $22 \%-73 \%$. Similar trends are found for a $2.5{ }^{\circ} \mathrm{C}$ target. Here, $650 \mathrm{ppm}$ provides a probability range of $0 \%-37 \% ; 450 \mathrm{ppm}$ a range from $40 \%-90 \%$.

Although we have not specifically targeted any rate of temperature change, a rate can be a useful proxy for the risk of adverse impacts from climate change (in particular ecosystems; see Fig. 11). In the baseline scenario, the rate of temperature change is around $0.25{ }^{\circ} \mathrm{C}$ per decade. In the mitigation scenarios, the rate of temperature increase drops significantly in particular in the second half of the century. In the $650 \mathrm{ppm}$ stabilization scenario, the rate drops below $0.2^{\circ} \mathrm{C}$ per decade around 2050 and below $0.1{ }^{\circ} \mathrm{C}$ in 2080 . In the 550 and 650 stabilization scenarios, the rate of change drops even further while, for 450 ppm $\mathrm{CO}_{2}$-eq., the rate actually falls below zero in 2100 . In the early decades (until 2030), the mitigation scenarios hardly perform any better than the baseline. The reason is that, in the mitigation scenarios, changes in the energy system to reduce $\mathrm{CO}_{2}$ emissions also lead to a reduction in sulphur cooling (as already emphasized by Wigley 1991). ${ }^{15}$ In our earlier calculations, in fact, this could even lead to an temporarily higher rate of temperature increase for some of our mitigation scenarios compared to baseline (van Vuuren et al. 2006b). The somewhat smaller impact here is mostly due to the increased potential to reduce non- $\mathrm{CO}_{2} \mathrm{GHGs}$, in combination with the higher overall rates of GHG emission reduction. By using GWPs as the basis of substitution between the different greenhouse gases, our method evaluates $\mathrm{CH}_{4}$ emission reduction as relatively cheap compared to reducing $\mathrm{CO}_{2}$ (see also van Vuuren et al. 2006c). As reducing $\mathrm{CH}_{4}$ is much less coupled to reducing sulphur and the impact of reducing $\mathrm{CH}_{4}$ on radiative forcing is much more direct, the high degree of $\mathrm{CH}_{4}$ reduction in our scenarios mitigates the impact of reduced sulphur cooling. This is somewhat comparable to the 'alternative' mitigation scenario suggested by Hansen et al. (2000).

${ }^{15}$ The impact of sulphur emissions on temperature increase is calculated in IMAGE based on the pattern scaling methodology that was developed by Schlesinger et al. (2000). 
Fig. 11 Rate of temperature change for 2000-2100 assuming a $2.5^{\circ} \mathrm{C}$ climate sensitivity



\subsection{Co-benefits and additional costs}

\subsubsection{Impacts on regional air pollutants}

Many air pollutants and GHGs have common sources. Their emissions interact in the atmosphere and, separately or jointly, cause a variety of environmental effects at the local, regional and global scales. Emission control strategies that simultaneously address air pollutants and GHGs may therefore lead to a more efficient use of resources at all scales. Current studies indicate that, when climate policies are in place, in the short-term (in particular the Kyoto period) potential co-benefits could be substantial, with financial savings in the order of $20 \%-50 \%$ of the abatement costs of the climate policy (e.g., van Vuuren et al. 2006a). In this study, we have focused our analysis on the consequences of climate policies for $\mathrm{SO}_{2}$ and $\mathrm{NO}_{x}$ emissions by using the same emission coefficients for $\mathrm{SO}_{2}$ and $\mathrm{NO}_{x}$ as those assumed under the baseline (reflecting similar policies for emissions of these substances), and simply quantifying the impact of changes in the energy system on emissions.

Figure 12 shows that the changes induced by climate policy in the energy system to reduce $\mathrm{CO}_{2}$ emissions also reduce $\mathrm{SO}_{2}$ emissions, in particular at lower reduction levels. This can be explained by the fact that coal in particular is used in conventional power plants,
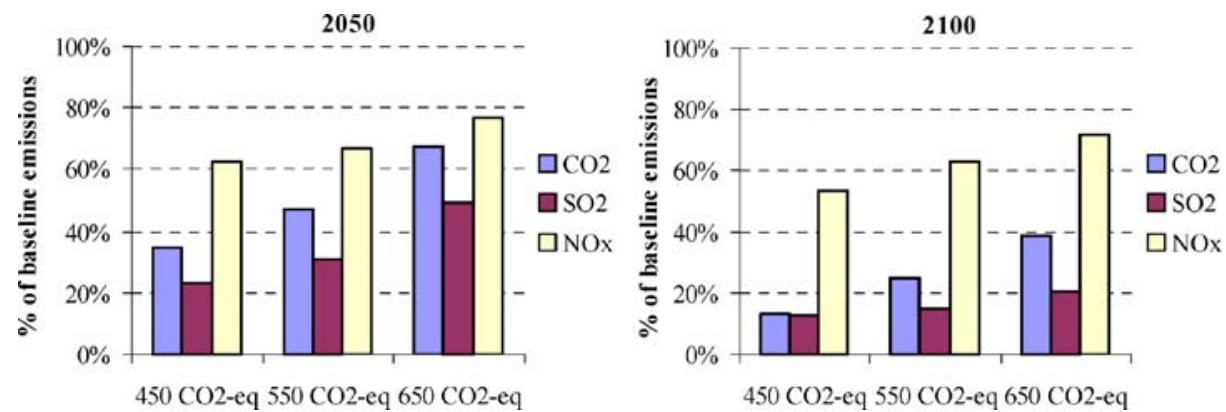

Fig. 12 Reduction of $\mathrm{CO}_{2}$ emission compared to baseline (baseline $=100 \%$ ) in the three B2 stabilization scenarios vs reductions of $\mathrm{SO}_{2}$ and $\mathrm{NO}_{x}$ emissions compared to baseline (2050 on left; 2100 on right) 
contributing to an even larger proportion of $\mathrm{SO}_{2}$ emissions than of $\mathrm{CO}_{2}$ emissions. Phasing out conventional fossil-fired power plants and reducing oil inputs into transport and replacing them by either fossil plants with CCS or renewables does significantly reduce $\mathrm{SO}_{2}$ emissions. In the case of $\mathrm{NO}_{x}$, there is a similar relationship between $\mathrm{CO}_{2}$ emission reductions and $\mathrm{NO}_{x}$ emission reductions - although here $\mathrm{NO}_{x}$ emissions reductions are smaller than those of $\mathrm{CO}_{2}$. The figures show that there are clear co-benefits for regional air pollution resulting from climate policy. In low-income countries, a focus on the potential synergies of climate change policies and air pollution policies could be even more important than in high-income countries. Synergy effects of climate policies on regional and urban air pollution may in fact be a reason for non-OECD countries to contribute to early emission reductions.

\subsubsection{Impacts on land use}

Several of the mitigation options considered have an impact on land use. Table 4 describes land use under the three main mitigation scenarios. As explained in Section 3, for bioenergy crops the modelling system may use $60 \%$ of the abandoned agricultural land and $25 \%$ of natural grassland or similar biomes. Carbon plantations may use $40 \%$ of abandoned agricultural land. In our scenarios significant amount of agricultural land are abandoned through the simulation period. In the first half of the century, this occurs in OECD regions and the former Soviet Union - mostly as result of a stabilizing food demand (due to a stabilizing population) and continuing yield increases (see IMAGE-team 2001b; Rosegrant et al. 2002; Strengers et al. 2004). In some developing regions (e.g., east Asia) similar dynamics may result in the availability of abandoned agricultural land in the second half of the century (Strengers et al. 2004). This result obviously depends on the yield improvements that are assumed in the scenario. The scenarios described here are based on the yield improvements reported in the Millennium Ecosystem Assessment (Carpenter and Pingali 2005).

In the mitigation scenarios, the most significant change compared to baseline is the increased demand for land for bio-energy: from 3.9 million $\mathrm{km}^{2}$ in the baseline scenario to 9.3 million $\mathrm{km}^{2}$ in the 450 ppm $\mathrm{CO}_{2}$-eq. stabilization scenario. This means that the bioenergy crop area is equal to about $50 \%$ of the total food and feed crop area in 2100. Most of this land is located in the former Soviet Union, South America, and the USA and, in the second part of the century, East Asia (see also Hoogwijk et al. 2004). In 2100, carbon plantations occupy about 2.6 million $\mathrm{km}^{2}$ (about $5 \%$ of all forest at that time). Here, most of the land is in the former Soviet Union, South America and again East Asia (Strengers et al. 2007). It should be noted that the agricultural land area for food and feed crops increases slightly, simply because some of the more productive areas are now used for either bio-energy or carbon plantations. The total 'domesticated' area increases by nearly $20 \%$

Table 4 Land use under the baseline (IMAGE 2.3 SRES B2 scenario) and mitigation scenarios in 2100 (million $\mathrm{km}^{2}$ )

\begin{tabular}{lcccc}
\hline & Baseline & $650 \mathrm{ppm} \mathrm{CO}$-eq. & $550 \mathrm{ppm} \mathrm{CO}$-eq. & 450 ppm $\mathrm{CO}_{2}$-eq. \\
\hline Agricultural land & 43.5 & 44.7 & 45.3 & 45.6 \\
Land for bio-energy & 3.9 & 9.3 & 9.3 & 10.2 \\
Land for carbon plantations & 0.0 & 1.6 & 2.2 & 2.6 \\
Total & 47.4 & 55.5 & 56.7 & 58.3 \\
\hline
\end{tabular}


while, in the baseline, land use in 2100 is virtually equal to land use in 2000. Land use does not differ much for the different stabilization scenarios as most of the bio-energy and carbon plantation potential is also used as part of the portfolio for stabilization at less ambitious levels. The question of whether the land-use consequences shown here lead to a similar loss of biodiversity is a more difficult one. The area used for bio-energy production and carbon plantations is mostly abandoned agricultural land (including both crop and pasture land), with also a considerable area coming from natural grass land. In the former case, at best secondary forest would have grown in these locations (although others have pointed out that, in many cases, land is not likely to recover automatically, in which case it will be transformed into degraded land). Moreover, it is to some degree possible to combine biodiversity targets and carbon plantations. The impact on biodiversity, therefore, is likely to be much smaller than the reduction suggested by looking at the land use impacts alone.

\section{Uncertainties in stabilizing emissions}

In the discussion of existing literature in Section 2, it was concluded the there are several categories of uncertainties that can substantially influence the results of stabilization scenarios. Here, we will discuss two of these: the baseline scenario and specific assumptions for individual technologies.

\subsection{Reducing emissions from different baselines}

Four scenario families were developed in the SRES report. Of these, the B2 scenario represented the most medium development. The A1b and B1 families led to higher and lower emissions respectively. Hourcade and Shukla (2001) showed the baseline to be just as important for mitigation costs as stabilization levels. We have therefore explored the influence of costs here on the basis of the implementation of these scenarios in the IMAGE 2.3 model. It should be noted that we have not included the A2 scenario. The reason is that the storyline of this scenario, i.e. little international cooperation and little focus on environmental issues, provides a very unfavourable situation for climate policy to be developed.

The A1b scenario leads to far higher per capita energy use than B2, although it has a lower population level and a lower share of coal in total energy use. Total GHG emissions are substantially higher than the B2 level, at around 26 GtC-eq. in 2050 and 25 GtC-eq. in 2100. The B1 scenario, by contrast, results in much lower energy use as a result of greater efficiency and lower population levels. Here, total GHG emissions peak in around 2050 at $15 \mathrm{GtC}$-eq. and decline thereafter to $8 \mathrm{GtC}$-eq. in 2100 . As a result, the emission reduction objectives for the different stabilization levels are larger for the A1b scenario and smaller for the B1 scenario (see also Fig. 3).

The costs of stabilization from these baselines for the low-range stabilization targets explored in this study are shown in Fig. 8. As expected (based on the higher baseline emissions), abatement costs for the A1b scenario are higher than those for the B2 scenario. In fact, the NPVs of abatement costs for each of the A1b stabilization cases are about double the costs of the corresponding B2 cases. By contrast, for B1, the costs of stabilization are substantially lower. In addition, across the range considered here, costs rise more slowly for $\mathrm{B} 1$ than in $\mathrm{A} 1 \mathrm{~b}$ and $\mathrm{B} 2$ as a result of a the smaller absolute gap between baseline emissions and the emissions under the stabilization case, the high technology development rate and the resulting lower marginal prices. 
6.2 Sensitivity to key assumptions for abatement options

Our analysis takes a wide range of abatement options into account. In all cases, the reduction potential and costs are subject to considerable uncertainties. The long time scale used (100 years) implies that assumptions need to be made about technology development, changes in implementation barriers and fundamental changes in the system as a whole; these may either assist or hinder certain reduction measures. As the uncertainties with regard to the individual options pile up in our combined assessment, we have therefore performed a sensitivity analysis for the $550 \mathrm{ppm} \mathrm{CO}_{2}$-eq. stabilizing scenario as indicated in Table 1 . The results are shown in Fig. 13.

In the case of emissions from the energy sector, one set of critical uncertainties include factors like the rate of technology change, lifestyle, economic growth and population dynamics. The impacts of these 'storyline-related' uncertainties have been explored earlier as part of the influence of the baseline scenario (A1b and B1) and taken together could impact costs by at least a factor 2. However, several other important uncertainties exist. As pointed out by Edmonds et al. (2004), the development of hydrogen technology itself is not strongly influenced by climate policy. However, once hydrogen is part of the system, stronger reductions are feasible than without hydrogen given the fact that hydrogen can - at relatively low additional cost - be produced without GHG emissions (Edmonds et al. 2004; van Ruijven et al. 2006). In the analysis, therefore, we explored the impact of a scenario with no hydrogen (a pessimistic assumption) and a scenario with large-scale penetration of hydrogen. The sensitivity to these assumptions was found to be small in 2050 (as the system hardly contains hydrogen) but substantial in 2100 (20\% difference in abatement costs either way).

Another important uncertainty concerns the potential of, and technology used for, bioenergy. As shown by Hoogwijk (2004), the uncertainty relating to bio-energy supply results in figures for potential use of between 100 and 800 EJ. In our central assumptions, the bioenergy use is about $400 \mathrm{EJ}$. We have lowered supply in our sensitivity runs for the pessimistic

a) Sensitivity in 2050

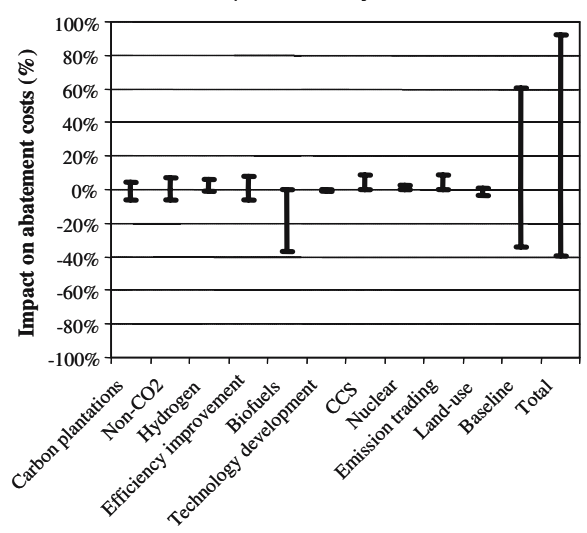

b) Sensitivity in 2100

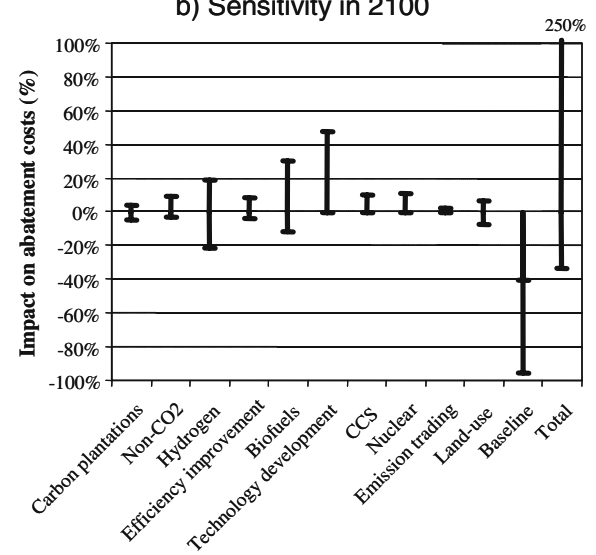

Fig. 13 Impacts of different uncertainties on global abatement costs as a percentage of GDP for stabilization at $550 \mathrm{ppm} \mathrm{CO}$-eq, 2050 (left) and 2100 (right). The column total is restricted to those assumptions that only impact the stabilization scenario; it therefore does not include the impacts of baseline and land-use 
case. Azar et al. (2006) have shown that including the option of bio-energy and carbon storage (BECS) can reduce costs at low concentration levels by at least $50 \%$. We will therefore use BECS for the high end of our range (see also 6.3). Figure 13 shows that this is in fact a very important uncertainty, influencing costs by about $40 \%$ downward (in the case of BECS) or $30 \%$ upwards (in case of restricted bio-energy supply). The influence of BECS is relatively low in long-run as the analysis is done for the $550 \mathrm{ppm}$ stabilization scenario - for which the reduction requirement in the long-run is still relatively low compared to the number of reduction options.

Another uncertainty relates to the contribution of energy efficiency. In the default run, we assumed that the permit price and international emissions trading leads to a convergence of investment criteria in energy efficiency worldwide towards levels that currently also apply to energy supply. In our sensitivity analysis, these assumptions ranged from full convergence towards supply-side criteria to no convergence. The influence of this factor is shown to be relatively modest - and to influence costs in 2100 by about $10 \%$ either way.

The results show that the cost-optimal implementation of the stabilization scenarios includes the large-scale use of CCS and nuclear power. For both options, not only technological uncertainties play an important role, but also social acceptability (for instance, at the moment several countries have indicated not to build new nuclear power plants). In this context, as a form of sensitivity analysis, we excluded both options (one by one). In each case, 2100 costs are about $10 \%$ higher. In 2050, the influence on costs is smaller. The reason for the relatively small impact is that by excluding only one option, the electric power sector still has enough reduction potential left to effectively respond to climate policy.

Another uncertain factor is induced technology change (in terms of investment costs) in response to climate policy. This factor is described by learning curves in the default run for solar, wind and nuclear power, bio-energy conversion, hydrogen production technologies, production of oil, natural gas and coal and costs of energy efficiency. In another paper, we showed that most of the 'learning' already occurs under the baseline scenario; the additional learning that results from the investments induced by climate policy is (in most cases) smaller than the baseline improvements (van Vuuren et al. 2004). In the sensitivity run, we set this second factor, induced technology change, to zero, implying that technology change in the mitigation scenario is equal to baseline development. While this factor is not important in the short run, it still represents a major uncertainty in the long run (around $50 \%$ costs increase), as shown in Fig. 13.

The effect of several crucial parameters that work directly on the supply and cost of carbon sequestration through plantations has been examined in Strengers et al. (2007). These parameters are the $\mathrm{CO}_{2}$ fertilization factor, the harvest regime, land costs, land use, the establishment costs, the discount rate and the increased growth rates of managed trees over natural trees (additional growth factor). Of these, the last factor proved to have most impact on outcomes. If the additional growth factor is reduced by $20 \%$, potential sequestration by carbon plantations was found to fall by about $37 \%$ and average cost of sinks increases sharply. On the other hand, an increase of $20 \%$ results in $33 \%$ more sequestration potential and a cost decrease of $35 \%$. Another important factor is the degree to which areas suitable for carbon plantation can actually be used for that purpose. A shortage of planting material, lack of knowledge and experience, other priorities for the land (e.g., bio-energy), etc. may reduce the abandoned agricultural area that can actually be planted. Waterloo et al. (2001) estimated that, in the case of CDM under the Kyoto Protocol, only $8 \%$ of the potential area would actually be available. This number could increase in time and with increasing permit prices. As a result, in our standard runs, we defined an exogenous implementation factor equal to $40 \%$ of the total potential. In the 
sensitivity runs, this factor varied between $20 \%$ and $50 \%$ respectively. However, the impact of these assumptions on overall global costs is relatively minor given the small contribution of carbon plantations to the total portfolio of reduction measures (about $5 \%$ of costs increase or decrease both in 2050 and 2100).

The non- $\mathrm{CO}_{2}$ reduction potential is based on the EMF-21 database and extrapolated for the period up to 2100 on the basis of assumptions about technological developments, and maximum reduction potentials and accompanying costs. Although there are uncertainties in the 2010 reduction potentials and costs, the major uncertainties are associated with the assumptions about future development. The assumptions about the maximum reduction potentials have most impact on the final outcomes. To assess this impact from a pessimistic perspective, we reduced the reduction potential by $20 \%$ - and increased costs by $20 \%$. In optimistic the case, we assumed the opposite. We found that sensitivity of overall costs to the non- $\mathrm{CO}_{2}$ assumptions are about $5 \%-10 \%$, comparable to the sensitivity to the carbon plantation assumptions.

Land use represents another major uncertainty. It impacts our results in several ways: (1) by influencing directly $\mathrm{CO}_{2}$ emissions from land use change, (2) by determining land available for carbon plantations and (3) by determining land available for bio-energy. With respect to $\mathrm{CO}_{2}$-emission-related changes in land use, it should be noted that even current base-year emission levels are highly uncertain. Houghton (2003) estimated carbon emissions at $2.2 \mathrm{GtC}$ per year, with an uncertainty range varying from 1.4 to $3.0 \mathrm{GtC}$ per year. Future projections for the carbon budget vary even more given uncertainties in the effect of $\mathrm{CO}_{2}$ fertilization, the response of soil respiration due to changes in climate and the uncertainties in future land-use patterns (Gitz and Ciais 2004; Leemans et al. 2002; Strengers et al. 2004). If we focus solely on the latter factor, future land-use change depends on both socio-economic developments and technological improvements in the agricultural system (Bruinsma 2003; Rosegrant et al. 2002). In the literature, there are different views about the possibilities of technological improvement (MA 2006). To take these uncertainties into account, we assessed the implications of uncertainties in technological improvement by varying the achieved agricultural yields - and recalculating $\mathrm{CO}_{2}$ emissions from land use change and the marginal abatement curves for carbon plantations and energy (bio-energy). We took the yield increase of the least positive scenario in the Millennium Ecosystem Assessment (order from strength) as a basis for the pessimistic run, and the yield increase from global orchestration as the most optimistic option in the MA. This variation provides an understanding of the importance of uncertainties in technological improvement for land-use emissions and potentials for bio-energy and carbon plantations. The impact of these assumptions on global costs is in the order of 5\%-10\% (in both directions).

We have not varied the other factors mentioned above for land-use related emissions such as $\mathrm{CO}_{2}$ fertilization and other parameters that influence the carbon cycle. The carbon cycle feedbacks are assumed at their IPCC TAR default values. It should be noted, however, that latest insights seem to suggest that carbon fertilization might be substantially weaker than assumed earlier. If that is the case, all greenhouse gas concentrations - in particular those for the higher concentration levels - will shift upward. Or, by the same token, more abatement action (and higher costs) will be needed to achieve the same stabilization level.

Discussed earlier in 6.1, Fig. 13 confirms that the baseline development is one of the most crucial uncertainties determining overall costs. The overall sensitivity here is in the order of $50 \%-100 \%$ (on the basis of the alternative B1 and A1b scenarios). The major role played by the baseline assumptions is to be expected since it changes the overall reduction objective, as well as technology assumptions, preferences for reduction options and GDP levels (used here as the nominator of the cost indicator). 
In the last sensitivity runs, we combined all high-cost and low-cost assumptions (except for baseline and land use). Variation was far higher than suggested by the individual options, especially on the high-cost side. The reason is that, without CCS and nuclear power as zerocarbon options in the electric power sector and with low bio-energy supply, this system is much less amenable to substantial emission reductions. While in one-by-one sensitivity analysis, the system has enough flexibility to substitute - in case all uncertainties play out in a negative way, this flexibility disappears.

So summarizing, among the most important parameters in terms of sensitivity of stabilization costs are the baseline, bio-energy, the presence of hydrogen, and the existence of learning-by-doing. Other important uncertainties are future land use (agricultural yields), bio-energy (the use of BECS), assumptions about efficiency improvement and, to some degree, the availability of CCS and nuclear power. The combined effect of all parameters can be far larger than the effect of individual options.

\subsection{Possibility of stabilizing at even lower levels}

In our analysis, we explored a set of scenarios that would lead to stabilization at levels as low as $450 \mathrm{ppm} \mathrm{CO}_{2}$-eq. In the previous section, we showed that there are important uncertainties in our analysis, some of which might lead to lower costs (and/or more reduction potential). With the more optimistic assumptions, it would also be possible to stabilize at lower levels than those explored in our central scenarios. Such scenarios will first overshoot the target concentration (given all delays in the system) and only start to approach this target by the end of the century. Of the uncertainties explored earlier, in particular more optimistic assumptions for land use, efficiency and bio-energy (both the available potential and the combination of bio-energy and CCS, BECS) could significantly increase reduction potential and thus allow reaching lower stabilization levels. Here, we specifically explored whether changing our assumptions for biofuels alone from the default assumption to the optimistic assumptions that allows the combination of BECS could be enough to reach the emission levels of a 400 ppm $\mathrm{CO}_{2}$-eq. The results, as indicated in Fig. 14, show that this change alone is sufficient to reach the emission pathway. An important element here is that adding BECS allows for a net carbon uptake during the growth of biofuels which is then

a) $\mathbf{B 2}$ baseline

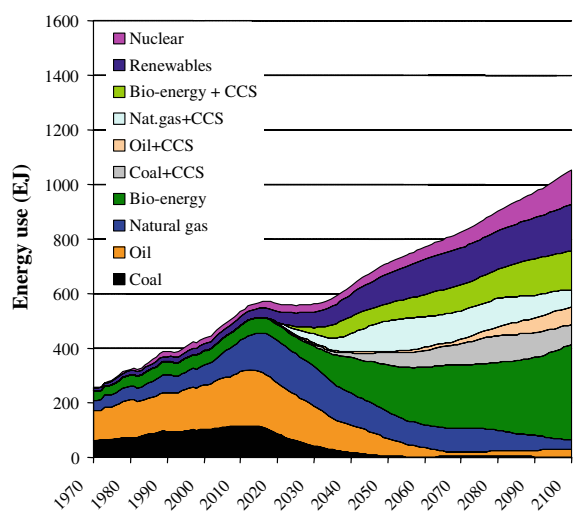

b) $450 \mathrm{CO}_{2}$-eq stabilization

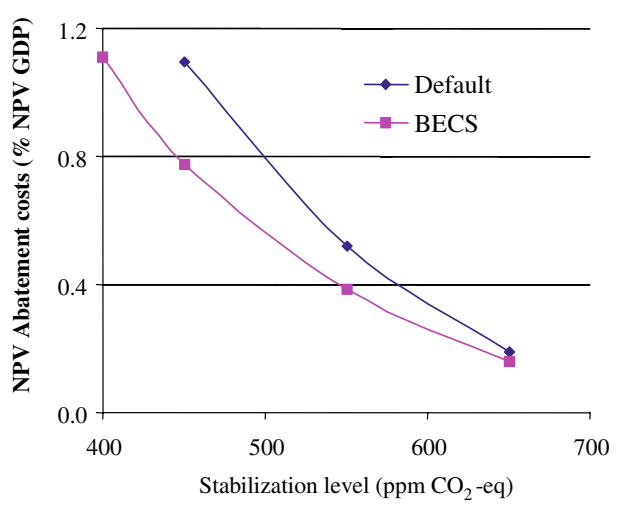

Fig. 14 Alternative scenario for stabilizing GHG concentration at $400 \mathrm{ppm} \mathrm{CO}_{2}$-eq. (left) and the associated costs (right) 
stored underground. These net 'negative emissions' are in particular important for low emission scenarios (see also Azar et al. 2006). The costs of BECS are a combination of the biofuel costs and CCS costs, which makes this technology certainly attractive at the permit price levels explored earlier for the $450 \mathrm{ppm} \mathrm{CO}_{2}$-eq. scenario. Thus, as a result of the more optimistic assumptions, our overall costs are comparable to our default case but this obviously requires conditions that allow for the achievement of this more optimistic view of technology development. This illustrated by Fig. 14b, where abatement costs are plotted for several stabilization levels both including and excluding BECS as abatement option.

\section{Discussion}

\subsection{Important limitations of the current study}

In this study, we used a linked set of integrated assessment models (TIMER, FAIR and IMAGE) to explore scenarios that lead to low GHG concentration levels using a multi-gas approach. There are a few important limitations to the study that are essential to interpreting the results:

- The cost concept used in this study refers to direct abatement cost only on the basis of marginal abatement curves derived from underlying expert models - and does not capture the macro-economic impacts of climate policy. Macro-economic cost measures (such as consumption or GDP losses, but also sectoral impacts) might in some cases be larger as they also include effects of loss of competitiveness, impacts on fuel trade, combined effects of climate policy and existing taxes etc. On the other hand, they can also be smaller, since there be will sectors and industries that profit from climate policy and since there might be benefits from recycling the revenues of carbon taxes (see Weyant 2000).

- The IMAGE 2.3 model does not explicitly model land use competition. For this reason, we have restricted the potential land use for climate policy (bio-energy, carbon plantations) to those areas that do not impact food production (i.e., abandoned agricultural land and natural grasslands). It might be interesting to explore how climate policy may impact food production in models that endogenously model competition for land.

- Not all reduction options are included. For instance, in the electric power system, emissions can also be reduced by geothermal power or concentrating solar power plants. However, as such technologies will compete mainly with other zero-carbon emission options; we do not think that including the new options will lead to significantly different results.

- The emission pathways are created by employing the FAIR-SiMCaP model that uses a different climate model (MAGICC) than IMAGE 2.3. Considerable attention, however, was given to making sure that the results of the two models were consistent. The remaining differences (e.g., up to about $10 \mathrm{ppm}$ for $\mathrm{CO}_{2}$ concentration) are certainly within the uncertainty ranges.

- In view of this being a long-term study, many assumptions are beset with uncertainty. This, for instance, is the case for assumptions on technological progress, and reduction potential. This has been taken care by an extensive sensitivity analysis (6.2).

- Finally, the most important limitation is that we do not deal with all kinds of societal barriers that exist in formulation ambitious climate policies. Such barriers may 
include the specific interests of different actors, inertia in international negotiations, other societal priorities etc. Instead, we assumed that all regions participate in climate policy (without necessarily paying for it) from 2013 onwards. This allowed us to explore, first, how ambitious climate stabilization strategies may look. In future research, it will be important to explore further which barriers exists - and how these may impact the results shown.

\subsection{Comparing the results to other studies}

As indicated in the introduction, there are hardly any other studies that describe mitigation strategies for all GHGs at relatively low concentration levels. Comparison therefore has to be made mostly on the basis of the $\mathrm{CO}_{2}$ concentration that is achieved in our scenarios (instead of total GHG forcing).

In terms of mapping mitigation costs as a function of stabilization levels, the main comparisons that can be made are with the studies summarized in the IPCC Third Assessment Report (TAR; these studies focus on $\mathrm{CO}_{2}$ only). Figure 15 shows the stabilization costs in terms of the discounted net present value as a function of $\mathrm{CO}_{2}$ concentration levels on the basis of this study, the TAR ranges and two more recent studies. Average cost values reported in IPCC TAR are around 0.8, 1.3 and 6.4 trillion US\$ for stabilizing at 650, 550 and $450 \mathrm{ppm}$ $\mathrm{CO}_{2}$ respectively (the lowest and highest values are typically $75 \%$ lower and two to three times higher respectively). The corresponding values found in this study are $0.5,1.7$ and 8 trillion (interpolating our results to the rounded-off concentration levels on the basis of the $\mathrm{CO}_{2}$ concentration in 2100). Our cost numbers, however, also include the mitigation costs for reducing non- $\mathrm{CO}_{2}$ gases (about 20\%-30\%). Given our baseline emissions (following the updated B2 scenario), and correcting for these non- $\mathrm{CO}_{2}$ costs, we can conclude that values found (including the trend) are generally consistent with those reported for $\mathrm{CO}_{2}$ stabilization studies. Azar et al. (2006) and Rao and Riahi (2006) also discuss similar cost levels as a function of concentration targets (again only for $\mathrm{CO}_{2}$ ) for considerably lower levels (here we report the results of their study for model runs that include fossil fuel CCS). Across the whole range of concentration levels, the function of costs as a function of lower

Fig. 15 Cost levels in this paper compared to alternative studies. All studies report the Net Present Value of mitigation costs (although some differences may result using different base years). The sources of the data shown are: EMF-16 results (Hourcade and Shukla 2001) (note that the EMF-16 results have been summarized here in terms of the highest and lowest values for different concentration levels across a range of models); IMAGE 2.2 (Azar et al. 2006; van Vuuren et al. 2006) and (Rao and Riahi 2006). From the latter two studies the data without the use of bioenergy carbon capture and storage are shown (to allow comparison)

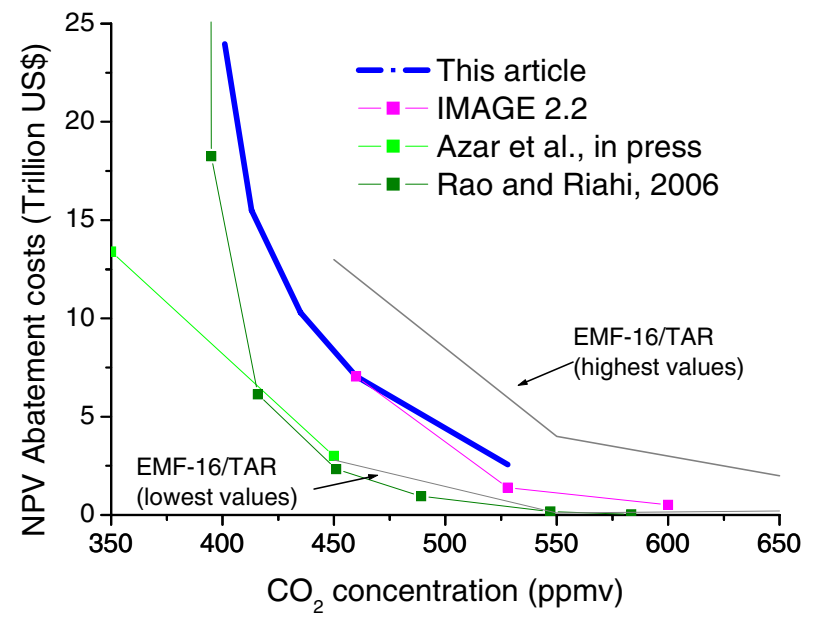


concentration level are comparable - although for individual concentration levels - costs may differ over a factor five. Reasons that may cause different costs levels (between all studies cited here) include differences in baseline, the number of options included and the technology assumptions for these options and the type of models.

For multi-gas stabilization strategies, comparison can be made with the results of EMF21 (van Vuuren et al. 2006c; Weyant et al. 2006). With only a few exceptions, the results of the models that participated in EMF-21 are only available for stabilization at $650 \mathrm{ppm} \mathrm{CO}_{2}-$ eq. In general terms, the findings described in this study seem to be consistent with those found in the EMF-21 study in terms of the contribution of non- $\mathrm{CO}_{2}$ gases and overall cost levels, but they extend them to lower levels. Given the wider range of abatement options considered (among others, a larger potential to reduce non- $\mathrm{CO}_{2}$ gases, a larger potential for carbon plantations, more possibilities to apply CCS), the marginal costs are lower than those presented by van Vuuren et al. (2006b).

\subsection{Dealing with uncertainties}

Uncertainty plays a dominant role in determining relevant targets for climate policy. Climate impacts are uncertain and - probably most importantly - climate sensitivity is very uncertain, creating a range of possible temperature outcomes for different stabilization levels, as indicated in Fig. 10. This paper has also shown that the potential and costs of several mitigation options are subject to major uncertainties.

Designing climate strategies that can manage different types of uncertainties will therefore be important. In this light, it is crucial to note that not all uncertainties are similar in nature. An important difference is the lag time between impact, the time when the impact becomes noticeable and the reversibility of the impact. It can still take decades before the uncertainty related to climate impacts and climate sensitivity is significantly reduced. Moreover, once the uncertainties are resolved (in whole or in part), the climate system may already be irreversibly on a path of 'dangerous anthropogenic interference' because of all the delays. Most of the uncertainties relating to mitigation options, however, are much more directly noticeable. For instance, if costs develop less favourably for major mitigation options, mid-course corrections can be made in either the portfolio of mitigation options used, the stabilization target or the financial budget (policies will not, after all, be cast in stone for the next 50 or 100 years). Similarly, if certain options prove less effective, they can be removed from the total package. There are some exceptions to this, however. One is that if a mitigation option leads to lock-in effects, a change of course might be less easy to accomplish. Secondly, in theory, $\mathrm{CCS}$ and nuclear power could lead to a situation of irreversible damage if the storage of $\mathrm{CO}_{2}$ or nuclear waste is not as safe as expected. In this light, what elements can be used to establish strategies that can cope with uncertainties?

First of all, such a strategy will include elements of hedging against climate risk. As described by Yohe at al. (2004), this in fact implies aiming in the short term for emissions pathways that do not exclude the possibility of reach low stabilization levels, thus providing options to avoid severe climate impact if climate sensitivity turns out to be at the upper range of the PDF. Secondly, monitoring of the most crucial uncertain elements will be important. Obviously, this particularly relates to parameters associated with temperature increase and climate impact, but also to the costs and potential of mitigation options. Thirdly, as much as possible, it will be necessary to select a portfolio of mitigation options instead of only a few options. As shown in this paper, a portfolio is in fact the result of the modelling that has taken place, but risk reduction is an additional argument not included in the modelling itself. A fourth element is flexibility in targets. Here, obviously, there is a 
trade-off between providing enough long-term certainty to actors involved in climate mitigation to make long-term investments attractive, while being flexible enough to deal with resolving uncertainty.

\section{Conclusions}

The main issue addressed by this paper was to indicate what portfolio of measures could constitute promising strategies for stabilizing GHG concentrations at low levels. The lowest multi-gas scenarios currently discussed in literature look at stabilization at $550 \mathrm{ppm} \mathrm{CO}_{2}$-eq. and higher. These scenarios have only a small change of limiting global mean temperature change to 2 or $2.5^{\circ} \mathrm{C}$. The main purpose of the present article was therefore trying to identify whether stabilization at lower concentration levels is feasible. Against this background, we developed a set of mitigation scenarios for stabilizing atmospheric GHG concentrations at 650,550 and $450 \mathrm{ppm} \mathrm{CO}_{2}$-eq., and - subject to specific assumptions $400 \mathrm{ppm}$. The scenarios focus on a larger set of mitigation options than most other studies, and extend the lower range of multi-gas scenarios currently discussed in the literature. The analysis leads to the following conclusions:

- The study shows that, technically, stabilizing greenhouse concentrations at 650, 550, $450 \mathrm{ppm}$ and, under specific assumptions, $400 \mathrm{ppm} \mathrm{CO}_{2}$-eq. is feasible from median baseline scenarios on the basis of known technologies.

In order to prevent 'dangerous anthropogenic interference with the climate system,' the stabilization of GHGs at low levels (e.g., 450 ppm $\mathrm{CO}_{2}$-eq. or below) might be needed. Currently, there are only a limited number of studies that identify mitigation strategies that could lead to such low stabilization levels - and none of these are based on a multi-gas approach. Here, we show that there are sufficient technical options to reduce emissions to the level required, and that these options can be combined into effective stabilization strategies. In fact, under favourable conditions, stabilization at $400 \mathrm{ppm}$ is also within the realm of technical possibility.

For 650 and $550 \mathrm{ppm} \mathrm{CO}_{2}$-eq. stabilization, it is possible to develop strategies that stabilize at these concentrations without overshooting the required target. For 450 ppm $\mathrm{CO}_{2}$-eq., overshooting this level before returning to the target during the twenty-second century seems unavoidable. For both $550 \mathrm{ppm} \mathrm{CO}_{2}$-eq. and 450 ppm $\mathrm{CO}_{2}$-eq. (and even lower levels), emissions have to peak within the next two decades followed by strong emission reductions. Our calculations show this to be the most difficult period for climate change policy, even assuming the full participation of all countries under a climate regime. The costs of not peaking global emissions within the next two decades could include higher temperature change and/ or more rapid emission reduction rates in the longer term (which can be costly if they would require premature replacement of capital).

- Creating the right socio-economic and institutional conditions for stabilization will represent the single most important step in any strategy towards GHG concentration stabilization.

The types of reductions described in this paper will require major changes in the energy system, stringent abatement action in other sectors and related large-scale investment in alternative technologies. Moreover, we have assumed that the world will find a mechanism to tap reduction potential in all parts of the world. In this context, creating the right socio-economic and institutional conditions that enable 
these transitions will be more important than any of the technologies discussed. This includes, among other things:

- Creating a sense of urgency about emission reduction in all parts of the world in order to develop an effective global climate regime;

- Creating conditions for technology development, and more importantly, technology dispersal and transfer;

- Overcoming current barriers to effective/cost-effective measures for reducing GHG emissions (e.g., information to improve investment in energy efficiency).

The impact of socio-economic and institutional conditions can also be illustrated by our analysis of the impact of alternative baseline scenarios. While stabilization at $450 \mathrm{ppm} \mathrm{CO}_{2}$-eq. represents a major challenge starting from the $\mathrm{B} 2$ baseline, the challenge is much smaller when starting from a B1 baseline.

- The net present value of abatement costs increases from $0.2 \%$ to $1.2 \%$ of the net present value of GDP (5\% discount rate) when moving from 650 to $450 \mathrm{ppm}$. On the other hand, the probability of meeting a two-degree target increases from $0 \%-18 \%$ to $22 \%-73 \%$.

In this paper, we have mapped out some of the costs and benefits of stabilizing GHGs at low levels. Costs clearly increase for lower levels of stabilization, but so do benefits. The net present value of stabilizing at $450 \mathrm{ppm} \mathrm{CO}_{2}$-eq. at our standard assumptions are about $1.2 \%$ of GDP (accumulated over the century), but they reach a peak of around $2 \%$ in the period $2040-2070$. At the same time, stabilization also provides clear benefits at low concentration levels. In order to achieve a certainty (on average) of at least $50 \%$ in reaching a $2{ }^{\circ} \mathrm{C}$ target, the $\mathrm{CO}_{2}$-eq. concentration needs stabilize at 450 ppm $\mathrm{CO}_{2}$-eq. or below.

In addition to direct abatement costs, stabilization also involves indirect costs and benefits. There are, for example, the consequences for the fuel trade. Stabilization policies are likely to reduce volume of global trade in fossil fuels, in particular oil and coal. This will reduce the exports of some countries, but at the same reduce imports of others. Regions that could export bio-energy may compensate some of reduced oil export by bio-energy exports. CCS does limit the impact of climate policy on fuel trade, especially for gas and coal.

- Strategies consist of a portfolio of measures. There is no magic bullet.

The reductions in our stabilization scenarios are achieved through a set of measures rather than a single measure. The reasons for this result include: (1) limitations in the potential of individual options, (2) regional and subregional differentiation, (3) increasing costs for penetration rates as a result of depletion, and (4) differentiation between different sectors. In addition to these model results, there is another important advantage of a strategy based on a portfolio of measures: the reduced risk if the development of a single technology is slower than expected (or even this technology is found unacceptable altogether, which could happen to nuclear power after a major accident). There is also an important disadvantage: the dispersal of R\&D capacity, learning-by-doing and economies of scale. However, we feel that this disadvantage is outweighed by the benefits mentioned above.

- Given our default assumptions, carbon capture and storage (CCS) represents a very attractive technology to reduce greenhouse gas emissions.

$\mathrm{CCS}$ could be the single most important technology for reducing $\mathrm{CO}_{2}$ emissions from the energy sector given its relatively low current costs estimates (IPCC 2005) compared to technologies that are chosen in the absence of climate policy. Its 
contribution could be around $30 \%-40 \%$ of total $\mathrm{CO}_{2}$ emissions reduced in the energy sector or $25 \%$ of total emission reductions. At the same time, the role played by CCS can, if necessary, be replaced by nuclear power and/or additional use of solar and wind power (at somewhat higher costs). It should be noted that these options are subject to several uncertainties. CCS has still to be proven in large-scale applications, and for CCS, nuclear power and wind power societal acceptance can play an important role determining their real potential. (see also the sensitivity analysis)

Other important contributions to overall emission reductions (in the absolute sense) under our default scenario include energy efficiency, the reduction of $\mathrm{CH}_{4}$ emissions, bio-energy and nuclear power and solar and wind power.

- Stringent stabilization strategies do result in co-benefits but also in additional costs.

The systemic changes in the energy system induced by stringent climate policy can result in important co-benefits. Emissions of regional air pollutants, in particular $\mathrm{SO}_{2}$ and $\mathrm{NO}_{x}$, will be reduced substantially, leading either to the improvement of regional and urban air pollution or to reduced abatement costs for these pollutants. Another co-benefit is the likely positive impact of climate policy on energy security issues (less dependency on oil imports). However, in addition to co-benefits, there will also be additional costs. The most important is that stringent climate policies are likely to lead to increased demand for land. This in turn could lead to impacts on biodiversity and possibly even food security.

- Uncertainties are important.

Uncertainty constitutes an important factor in the development of stabilization strategies, in particular with respect to the reduction rates required. In this paper, we also focused on other sets of uncertainties relating to the effectiveness and cost of mitigation options. These uncertainties are partly caused by uncertainty with respect to technology development, but also by public attitudes (e.g., acceptance of nuclear power, CCS or large-scale bio-energy). Together, these uncertainties can easily double or halve the mitigation costs for a certain mitigation target, or even put certain targets out of reach. Crucial uncertainties, for instance, include those related to land use, baseline emissions, bio-energy use and potential and technology development. Climate policies should therefore include strategies that can cope with these uncertainties.

Acknowledgments The authors would like to thank other members of the Climate and Global Sustainability team of MNP, in particular Bert de Vries, Rineke Oostenrijk, Marcel Berk and Monique Hoogwijk. We also would like to thank Malte Meinshausen, Christian Azar and an anonymous reviewer for their comments that allowed us to improve the manuscript considerably.

\section{Appendix: model description}

A brief description of the model - and how these models are connected is already included in the main text. This appendix provides additional information - while for detailed model descriptions, the reader is referred to model documentation which has been published elsewhere.

Description of the models used

\section{The FAIR-SiMCaP 1.1 model}

The FAIR 2.1 model (framework to assess international regimes for differentiation of future commitments) was designed to quantitatively explore the outcomes of different climate re- 
gimes in terms of possible environmental and economic impacts (including emission trading). It is a decision-support tool with at its core the option to design rule-based systems that simulate different proposals for differentiating of future commitments ('burden sharing'). The model uses expert information from more complex models such as baseline emissions and marginal abatement costs curves (in particular, TIMER and IMAGE) to calculate the consequences of these proposals. The basic assumption of the model is that regions will reach their emission reduction commitments on the basis of least cost - i.e., across different mitigation options (multi-gas) and across different regions (set by certain trading rules). Recently, the FAIR 2.1 has been integrated with the SiMCaP 1.0 model allowing simultaneous calculations of climate impacts based on the MAGICC model (Wigley and Raper 2001) included in SiMCaP. Extensive documentation of the FAIR 2.1 model can be found in den Elzen and Lucas (2005) and FAIR-SiMCaP 1.1 model in den Elzen and Meinshausen (2005).

\section{The TIMER model}

The global energy system model TIMER (The Image Energy Regional model) has been developed to simulate (long-term) energy baseline and mitigation scenarios. The model describes the investments in, and the use of, different types of energy options influenced by technology development (learning-by-doing) and resource depletion. Inputs to the model are macro-economic scenarios and assumptions on technology development, preference levels and restrictions to fuel trade. The output of the model demonstrates how energy inensity, fuel costs and competing non-fossil supply technologies develop over time. In TIMER, implementation of mitigation is generally modelled on the basis of price signals (a tax on carbon dioxide). A carbon tax (used a generic measure of climate policy) induces additional investments in energy efficiency, fossil fuel substitution, and investments in bioenergy, nuclear power, solar power, wind power and carbon capture and storage. Selection of options throughout the model is based on a multinomial logit model that assigns market shares on the basis of production costs and preferences (cheaper, more attractive options get a larger market share; but there is no full optimization).

The TIMER model has been described in detail (de Vries et al. 2001). The model includes the following primary energy sources: coal, oil, natural gas, bio-energy, solar power, wind power, hydro power, and nuclear power. In terms of secondary energy carriers, it includes direct converted fuels based on the primary sources listed above and electricity, heat and hydrogen.

\section{The IMAGE 2 model}

The IMAGE 2 integrated assessment model describes important elements of the cause (response chain of global environmental change and has been described in detail elsewhere (Alcamo et al. 1998; IMAGE-team 2001b). In the model, socio-economic processes are mostly modelled at the level of 17 world regions, while climate, land-use and several environmental parameters are modelled at a $0.5 \times 0.5$ degree resolution. The models main model components are the land-use and land cover model, a climate model and several impact models (e.g., impacts on crops and soil degradation risk). The land-use and land cover model distinguishes 14 natural and forest land-cover types and five man-made landcover types. A crop module based on the FAO agro-ecological zones approach computes yields of the different crops and pastures, estimating the areas used for their production as determined by climate and soil quality (Alcamo et al. 1998). In case expansion of agricultural land is required to satisfy growth of food demand, a rule-based 'suitability map' determines 
which grid cells are selected. IMAGE also includes a modified version of the BIOME mode (Prentice et al. 1992) to compute changes in potential vegetation. The climate model of IMAGE (Eickhout et al. 2004) is an adapted version of the MAGICC model (Wigley and Raper 2001); the carbon cycling modelling is integrated within the IMAGE's detailed description of the biosphere, and the ocean-carbon uptake is replaced by the Bern model (Joos et al. 1996). Patterns scaling methods are next used to calculate climate change at the level of a $0.5 \times 0.5$ grid. The modelling of land-use related greenhouse gas emissions in IMAGE are based on detailed description of the physical drivers such as land use change and animal production.

Table 5 Assumptions within the TIMER model for various energy categories

\begin{tabular}{|c|c|c|}
\hline Option & Assumptions & References \\
\hline Fossil fuels & $\begin{array}{l}\text { Regional resources and production costs for various } \\
\text { qualities; global trade (coal, oil and natural gas resources } \\
\text { equal } 300,45 \text {, and } 117 \mathrm{ZJ} \text { respectively). Global average } \\
\text { crude energy prices in } 2050 \text { are } 1.4,5.1 \text { and } 4.41995 \mathrm{US} \$ \text { / } \\
\text { GJ for respectively coal, oil and natural gas. In } 2000 \text {, these } \\
\text { prices are } 1.1,3.0 \text { and } 2.31995 \mathrm{US} \$ \text { GJ }\end{array}$ & (Rogner 1997) \\
\hline $\begin{array}{l}\text { Carbon capture and } \\
\text { storage }\end{array}$ & $\begin{array}{l}\text { Regional reservoir availability and storage costs for various } \\
\text { options (different categories of empty oil, natural gas and } \\
\text { coal reservoirs, coal-bed methane recovery, aquifers). Total } \\
\text { capacity equals } 1,500 \text { GtC. Transport and storage costs } \\
\text { range (depending op category and region) from } 10-150 \\
\text { US\$ } / \mathrm{tC}\end{array}$ & $\begin{array}{l}\text { (Hendricks et al. } \\
\text { 2002) }\end{array}$ \\
\hline $\begin{array}{l}\text { Power plant efficiency } \\
\text { and investment costs }\end{array}$ & $\begin{array}{l}\text { Power plant efficiency and investment costs for } 20 \text { types of } \\
\text { thermal power plants (coal, oil, natural gas, biomass) } \\
\text { including carbon capture and storage defined over time }\end{array}$ & $\begin{array}{l}\text { (Hendricks et al. } \\
\text { 2004) }\end{array}$ \\
\hline Biomass & $\begin{array}{l}\text { Potential and costs for primary biomass defined by region } \\
\text { on the basis of IMAGE } 2 \text { maps (including abandoned } \\
\text { agricultural land, natural grasslands and savannah). } \\
\text { Primary biomass can be converted into liquid biofuels (for } \\
\text { transport) and solid bio-energy (for electricity). } \\
\text { Technology development is based on learning-by-doing. } \\
\text { Maximum potential equals } 230 \text { EJ in } 2050 \text { and } 600 \text { EJ in } \\
2100 \text {. Production costs for liquid fuels varies between } 16 \\
\text { \$GJ in } 2000 \text { and around } 10 \text { \$GJ (depending on scenario). } \\
\text { Production costs for solid fuels varies around } 4 \text { \$GJ }\end{array}$ & $\begin{array}{l}\text { (Hoogwijk } \\
\text { 2004) }\end{array}$ \\
\hline Solar/wind power & $\begin{array}{l}\text { Solar and wind power based on studies that assess global } \\
\text { potential on the basis of } 0.5 \times 0.5 \text { degree maps. Costs } \\
\text { change over time as a result of depletion, learning-by- } \\
\text { doing and grid penetration (declining capacity-credit and } \\
\text { excess electricity production) }\end{array}$ & $\begin{array}{l}\text { (Hoogwijk } \\
\text { 2004) }\end{array}$ \\
\hline Nuclear power & $\begin{array}{l}\text { Investment costs of nuclear power based on available } \\
\text { information in literature (most important references } \\
\text { indicated). Investments costs are assumed to decrease over } \\
\text { time. Fuel costs increase over time as result of depletion }\end{array}$ & $\begin{array}{l}\text { MIT 2003; } \\
\text { Sims et al. } \\
\text { 2003) }\end{array}$ \\
\hline Hydrogen & $\begin{array}{l}\text { Hydrogen modelled on the basis of production from fossil } \\
\text { fuels, bio-energy, electricity and solar power (including } \\
\text { carbon capture and storage). Selection on the basis of a } \\
\text { multinomial logit model }\end{array}$ & $\begin{array}{l}\text { (van Ruijven et } \\
\text { al. 2006) }\end{array}$ \\
\hline
\end{tabular}


Table 6 Overview of reduction potential under the main baseline (B2)

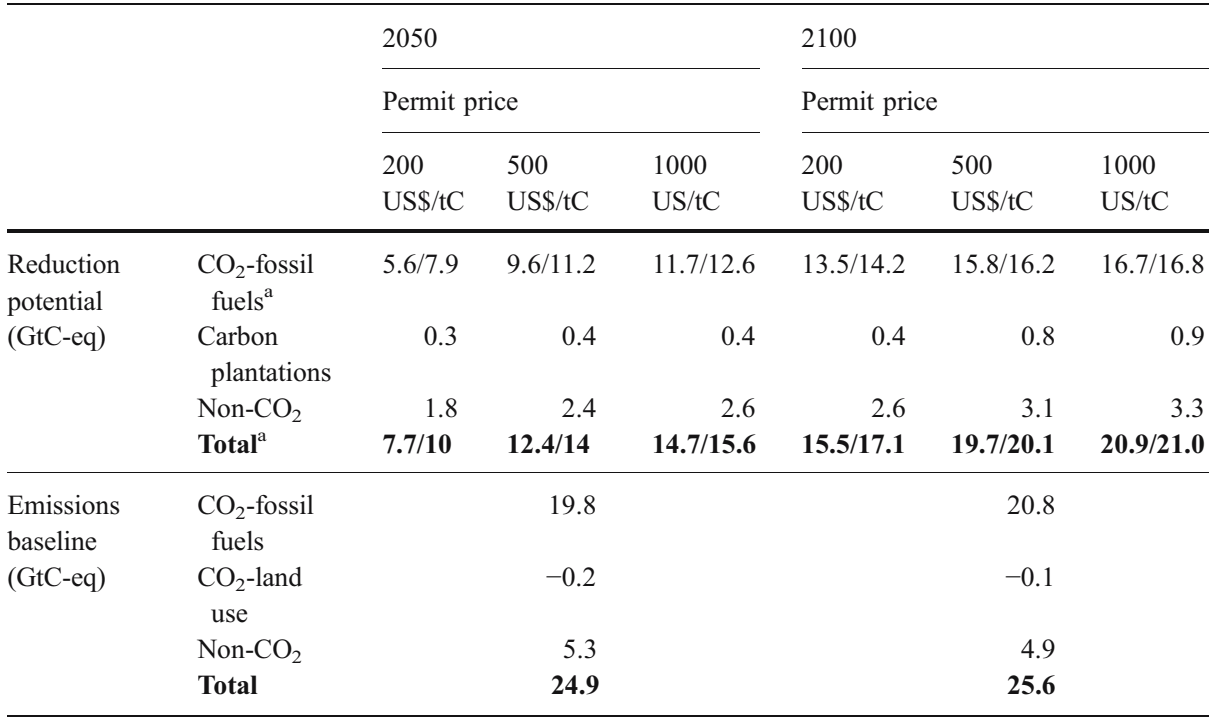

${ }^{\mathrm{a}}$ For $\mathrm{CO}_{2}$ from fossil fuels, the maximum reduction potential depends on the trajectory of the carbon tax. Indicated are (left and right of the '/ sign) the minimum and maximum reduction potential based on a linearly increasing and block tax profile.

\section{Specific assumptions on mitigation potential}

In addition to the overall description of mitigation options in the main text, here we briefly indicate some of the quantitative assumptions and detailed references.

a. Energy. The main assumptions in the energy model for the various energy categories are indicated in Table 5.

b. Total marginal abatement curves

The total reduction potential per main reduction category is indicated in Table 6 .

\section{References}

Alcamo J, Kreileman E, Krol M, Leemans R, Bollen J, van Minnen J, Schaeffer M, Toet S, de Vries HJM (1998) Global modelling of environmental change: on overview of IMAGE 2.1. In: Alcamo J, Leemans R, Kreileman E (eds) Global change scenarios of the 21st century. Results from the IMAGE 2.1 model. Elsevier Science, London, pp 3-94

Azar C (1998) The timing of CO2 emissions reductions: the debate revisited. Int J Environ Pollut 10: $508-521$

Azar C, Rodhe H (1997) Targets for stabilization of atmospheric CO2. Science 276:1818-1819

Azar C, Dowlatabadi H (1999) A review of technical change in assessment of climate policy. Annu Rev Energy Environ 24:513-544

Azar C, Lindgren K, Larson E, Möllersten K (2006) Carbon capture and storage from fossil fuels and biomass - costs and potential role in stabilizing the atmosphere. Clim Change 74(1-3):47-79

Barker T, Pan H, Koehler J, Warren R, Winne S (2005) Induced technological change in the stabilisation of carbon dioxide concentrations in the atmosphere: scenario using a large-scale econometric model. In: Schellnhuber HJ, Cramer W, Nakicenovic N, Wigley T, Yohe G (eds) Avoiding dangerous climatic change. Cambridge University Press, Cambridge, UK 
Berk M, van Minnen J, Metz B, Moomaw W, den Elzen M, van Vuuren DP, Gupta J (2002) Climate OptiOns for the Long term (COOL). Global Dialogue - Synthesis Report. MNP Netherlands Environmental Assessment Agency, Bilthoven. www.mnp.nl/en

Bruinsma J (2003) World agriculture: towards 2015/2030. An FAO perspective. EarthScan, London

Carpenter S, Pingali P (2005) Millennium Ecosystem Assessment - scenarios assessment. Island Press, Washington, District of Columbia

Corfee Morlot J, Smith J, Agrawala S, Franck T (2005) Article 2, Long-term goals and post-2012 commitments: where do we go from here with climate policy? Climate Policy 5(3)

Criqui P, Kitous A, Berk MM, den Elzen MGJ, Eickhout B, Lucas P, van Vuuren DP, Kouvaritakis N, Vanregemorter D (2003) Greenhouse gas reduction pathways in the UNFCCC Process up to $2025-$ Technical Report. CNRS-IEPE, Grenoble, France

de Beer J (1998) Potential for industrial energy efficiency improvement in the long term. Department of Science, Technology and Society, Utrecht University

de Vries HJM, van Vuuren DP, den Elzen MGJ, Janssen MA (2001) The Targets Image Energy model regional (TIMER) - Technical documentation. MNP Netherlands Environmental Assessment Agency, Bilthoven, the Netherlands. www.mnp.nl/en

den Elzen MGJ, Lucas P (2005) The FAIR model: a tool to analyse environmental and costs implications of climate regimes. Environ Model Assess 10(2):115 - 134

den Elzen MGJ, Meinshausen M (2005) Meeting the EU 2 degree target: global and regional emission implications. MNP Netherlands Environmental Assessment Agency, Bilthoven, The Netherlands. www.mnp.nl/en

den Elzen M, Lucas P, van Vuuren DP (2006) Regional abatement costs and options under allocation schemes for emission allowances for low CO2-equivalent concentrations (submitted)

den Elzen MGJ, Meinshausen M, van Vuuren DP (2007) Multi-gas emission envelopes to meet greenhouse gas concentration targets: costs versus certainty of limiting temperature increase. Glob Environment Change. doi:10.1016/j.gloenvcha.2006.10.003 (accepted for publication)

ECF and PIK (2004) What is dangerous climate change? Initial Results of a Symposium on Key Vulnerable Regions, Climate Change and Article 2 of the UNFCCC. European Climate Forum and Postdam Institute for Climate Impact Research. http://www.european-climate-forum.net/pdf/ECF_beijing_results.pdf

Edmonds JA, Clarke J, Dooley J, Kim SH, Smith SJ (2004) Modelling greenhouse gas energy technology responses to climate change. Energy 29:1529-1536

Eickhout B, Den Elzen MGJ, Kreileman GJJ (2004) The Atmosphere-Ocean System of IMAGE 2.2. A global model approach for atmospheric concentrations, and climate and sea level projections. MNP Netherlands Environmental Assessment Agency, Bilthoven. www.mnp.nl/en

EU (1996) Communication of the community strategy on climate change. Council of the EU

EU (2005) Council of the European Union, Presidency conclusions, March 22-23. http://ue.eu.int/ueDocs/ cms_Data/docs/pressData/en/ec/84335.pdf

Gitz V, Ciais P (2004) Future expansion of agriculture and pasture acts to amplify atmospheric CO2 in response to fossil fuel and land-use change emissions. Clim Change 67:161-184

Graveland C, Bouwman AF, de Vries HJM, Eickhout B, Strengers BJ (2002) Projections of multi-gas emissions and carbon sinks, and marginal abatement cost functions modelling for land-use related sources. MNP Netherlands Environmental Assessment Agency, Bilthoven. www.mnp.nl/en

Ha-Duong M, Grubb MJ, Hourcade JC (1997) Influence of socioeconomic inertia and uncertainty on optimal CO2-emission abatement. Nature 390(6657):270-273

Hammitt JK, Lempert RJ, Schlesinger ME (1992) A sequential-decision strategy for abating climate change. Nature 357:315

Hansen J, Sato M, Ruedy R, Lacis A, Oinas V (2000) Global warming in the twenty-first century: an alternative scenario. PNAS 97(18):9875-9880

Hare WL, Meinshausen M (2004) How much warming are we committed to and how much can be avoided? Potsdam Institute for Climate Impact Research (PIK), Potsdam, Germany. http://www.pik-potsdam.de/ publications/pik_reports

Hendriks C, Graus W, van Bergen F (2002) Global carbon dioxide storage potential and costs. Ecofys, Utrecht

Hendriks C, Harmelink M, Burges K, Ransel K (2004) Power and heat productions: plant developments and grid losses. Ecofys, Utrecht

Hijioka Y, Masui T, Takahashi K, Matsuoka Y, Harasawa H (2006) Development of a support tool for greenhouse gas emissions control policy to help mitigate the impact of global warming. Environ Econ Policy Stud 7(3):331-347

Hoogwijk M (2004) On the global and regional potential of renewable energy sources. PhD-thesis. Science, Technology and Society, Utrecht University

Hoogwijk M, de Vries HJM, Turkenburg WC (2004) Assessment of the global and regional geographical, technical and economic potential of onshore wind energy. Energy Econ 26:889-919 
Houghton RA (2003) Revised estimates of the annual net flux of carbon to the atmosphere from changes in land use and land management 1850-2000. Tellus 55B:378-390

Hourcade JC, Shukla P (2001) Global, regional and national costs and ancillary benefits of mitigation. In: Metz B, Davidson O, Swart R, Pan J (eds) Climate change 2001: mitigation. Cambridge Univ. Press, Cambridge

IEA (2004a) CO2 capture and storage. International Energy Agency, Paris

IEA (2004b) World energy outlook 2004. International Energy Agency, Paris

IMAGE-team (2001a) The IMAGE 2.2 implementation of the SRES scenarios. A comprehensive analysis of emissions, climate change and impacts in the 21 st century Bilthoven, The Netherlands

IMAGE-team (2001b) The IMAGE 2.2 implementation of the SRES scenarios. Climate change scenarios resulting from runs with several GCMs. Netherlands Environmental Assessment Agency (MNP), Bilthoven, The Netherlands

IPCC (2001) Climate change 2001 - synthesis report. Cambridge Univ. Press, Cambridge

IPCC (2005) Special report on CO2 capture and storage. Cambridge Univ. Press, Cambridge

Joos F, Bruno M, Fink R, Siegenthaler U, Stocker TF, Le Quéré C, Sarmiento JL (1996) An efficient and accurate representation of complex oceanic and biospheric models of anthropogenic carbon uptake. Tellus 48B:397-417

Kaya (1989) Impacts of carbon dioxide emissions on GWP: interpretation of proposed scenarios. IPCC/ Response Strategies Working Group, Geneva

Leemans R, Eickhout BE (2004) Another reason for concern: regional and global impacts on ecosystems for different levels of climate change. Glob Environ Change 14:219-228

Leemans R, Eickhout B, Strengers BJ, Bouwman AF, Schaefer M (2002) The consequences for the terrestrial carbon cycle of uncertainties in land use, climate and vegetation responses in the IPCC SRES scenarios. Science China, Ser C 45:126-136

Lucas PL, van Vuuren DP, Olivier JGJ, den Elzen MGJ (in press) Long-term reduction potential of non-CO2 greenhouse gases. Environ Sci Policy. doi:10.1016/j.envsci.2006.10.007

Lucas PL, Den Elzen MGJ, van Vuuren DP (2005) A multi-gas abatement analysis of the Kyoto Protocol. Netherlands Environmental Assessment Agency (MNP), Bilthoven, The Netherlands

MA (2006) Ecosystems and human well-being: scenarios. Findings of the Scenarios Working Group. Island Press, Washington

Manne AS, Richels R (2004) The impact of learning-by-doing on the timing and costs of CO2 abatement. Energy Econ 26:603-619

Mastandrea MD, Schneider SH (2004) Probabilistic integrated assessment of dangerous climate change. Science 304:571-574

Matthews BJH, van Ypersele JP (2003) UNFCCC Article 2, stabilisation and uncertainty: engaging citizens with a web-based climate model (http://www.chooseclimate.org/confpres/stabshiftuncert5.doc)

Meinshausen M (2006) On the risk of overshooting $2{ }^{\circ} \mathrm{C}$. In: Schellnhuber HJ, Cramer W, Nakicenovic N, Wigley T, Yohe G (eds) Avoiding dangerous climate change. Cambridge University Press, Cambridge, UK

Meinshausen M, Hare B, Wigley TML, van Vuuren DP, den Elzen MGJ, Swart R (2006) Multi-gas emission pathways to meet climate targets. Clim Change 75(1-2):151-194

Metz B, van Vuuren DP (2006) How, and at what costs, can low-level stabilisation be achieved? - An overview. In Schellnhuber HJ, Cramer W, Nakicenovic N, Wigley T, Yohe G (eds) Avoiding dangerous climate change. Cambridge Univ. Press, Cambridge

MIT (2003) The future of nuclear power - an interdisciplinary MIT study. Massachusetts Institute of Technology, Cambridge, USA

MNP (2005) Limits to global warming. Netherlands Environmental Assessment Agency (MNP), Bilthoven

Morita T, Robinson J (2001) Greenhouse gas emission mitigation scenarios and implications. In: Metz B, Davidson O, Swart R, Pan J (eds) Climate change 2001: mitigation. Cambridge Univ. Press, Cambridge

Morita T, Nakicenovic N, Robinson J (2000) Overview of mitigation scenarios for global climate stabilization based on new IPCC emission scenarios (SRES). Environ Econ Policy Stud 3:65-88

Murphy J (2004) Quantification of modelling uncertainties in a large ensemble of climate change simulations. Nature 430:768-772

Nakicenovic N, Riahi K (2003) Model runs with MESSAGE in the context of the further development of the Kyoto Protocol. International Institute for Applied Systems Analysis

Nakicenovic et al. (2000a) Special Report on Emissions Scenarios (SRES). Cambridge Univ. Press, Cambridge, UK

Nakicenovic N, Alcamo J, Davis G, De Vries B, Fenhamm J, Gaffin S, Gregory K, Gruebler A, Jung TY, Kram T, Lebre La Rovere E, Michaelis L, Mori S, Morita T, Pepper W, Pitcher H, Price L, Riahi K, Roehrl A, Rogner HH, Sankovski A, Schlesinger M, Shukla P, Smith S, Swart R, Van Rooyen S, Victor N, Zhou D (2000b) IPCC Special report on emissions scenarios. Cambridge Univ. Press, Cambridge

NIES (2005) Emission scenario database. National Institute for Environmental Studies, Japan 
O’Neill BC, Oppenheimer M (2002) Climate change: dangerous climate impacts and the Kyoto Protocol. Science 296:1971-1972

Prentice IC, Cramer W, Harrison SP, Leemans R, Monserud RA, Solomon AM (1992) A global biome model based on plant physiology and dominance, soil properties and climate. J Biogeogr 19:117-134

Rao S, Riahi K (2006) The role of non- $\mathrm{CO}_{2}$ greenhouse gases in climate change mitigation: long-run scenarios for the $21^{\text {st }}$ century. Energy J. Special Issue

Richels RG, Manne AS, Wigley TML (2004) Moving beyond concentrations: the challenge of limiting temperature change. AEI-Brookings Joint Center, Washington, District of Columbia

Rogner HH (1997) An assessment of world hydrocarbon resources. Annu Rev Energy Environ 22:217-262

Rosegrant MW, Cai X, Cline S (2002) World water and food to 2025: dealing with scarcity. International Food Policy Research Institute, Washington, District of Columbia

Schlesinger ME, Malyshev S, Rozanov EV, Yang F, Andronova NG, de Vries HJM, Grübler A, Jiang K, Masui T, Morita T, Nakicenovic N, Penner J, Pepper W, Sankovski A, Zhang Y (2000) Geographical distributions of temperature change for scenarios of greenhouse gas and sulphur dioxide emissions. Technol Forecast Soc Change 65(167-193)

Sims REH, Rogner HH, Gregory K (2003) Carbon emission and mitigation cost comparisons between fossil fuel, nuclear and renewable energy resources for electricity generation. Energy Policy 31:1315-1326

Strengers BJ, Leemans R, Eickhout B, de Vries B, Bouwman AF (2004) The land use projections in the IPCC SRES scenarios as simulated by the IMAGE 2.2 model. GeoJournal 61(4):381-393

Strengers BJ, van Minnen J, Eickhout B (2007) The role of carbon plantations in mitigating climate change: potentials and costs. Clim Change (accepted for publication)

Swart R, Mitchell J, Morita T, Raper S (2002) Stabilisation scenarios for climate impact assessment. Glob Environ Change 12(3):155-165

UN (2004) World population to 2300. United Nations, New York

van Ruijven B, van Vuuren DP, de Vries B (2006) The potential role of hydrogen in energy systems with and without climate policy (in press)

van Vuuren DP, O'Neill BC (2006) The consistency of IPCC's SRES scenarios to 1990-2000 trends and recent projections. Clim Change 75(1-2):9-46

van Vuuren DP, den Elzen MG, Berk MM, Lucas PL, Eickhout B, Eerens H, Oostenrijk R (2003) Regional costs and benefits of alternative post-Kyoto climate regimes. Netherlands Environmental Assessment Agency (MNP), Bilthoven, The Netherlands

van Vuuren DP, de Vries HJM, Eickhout B, Kram T (2004) Responses to technology and taxes in a simulated world. Energy Econ 26(4):579-601

van Vuuren DP, Cofala J, Eerens HE, Oostenrijk R, Heyes C, Klimont Z, den Elzen MGJ, Amann M (2006a) Exploring the ancillary benefits of the Kyoto Protocol for air pollution in Europe. Energy Policy 34 (4):444- 460

van Vuuren DP, Eickhout B, Lucas P, den Elzen MGJ (2006b) Long-term multi-gas scenarios to stabilise radiative forcing - exploring costs and benefits within an integrated assessment framework. Energy J. Special Issue

van Vuuren DP, Weyant J, De la Chesnaye F (2006c) Multigas scenarios to stabilise radiative forcing. Energy Econ 28(1):102-120

Waterloo MJ, Spiertz PH, Diemont H, Emmer I, Aalders E, Wichink-Kruit R, Kabat P (2001) Criteria potentials and costs of forestry activities to sequester carbon within the framework of the clean development mechanism. Alterra Green World Research, Wageningen, The Netherlands

Weyant JP (2000) An introduction to the economics of climate change policy. Pew Center on Global Climate Change. Washington DC

Weyant JP, De la Chesnaye FC, Blanford G (2006) Overview of EMF - 21: multigas mitigation and climate change. Energy $\mathrm{J}$ (in press)

White-House (2002) Executive summary of Bush climate change initiative (http://www.whitehouse.gov/ news/releases/2002/02/climatechange.html)

Wigley TML (1991) Coud reducing fossil-fuel emissions cause global warming. Nature 349:503-506

Wigley TML (2003) Modelling climate change under no-policy and policy emissions pathways. Organisation for Economic Co-operation and Development, Paris

Wigley TML, Raper SCB (2001) Interpretation of high projections for global-mean warming. Science 293:451-454

Wigley TML, Richels R, Edmonds JA (1996) Economic and environmental choices in stabilisation of atmospheric CO2 concentrations. Nature 369:240-243

Yohe G, Andronova N, Schlesinger M (2004) To hedge or not to hedge against an uncertain climate future? Science 306:416-417 